\title{
REVELANDO LA ICONOGRAFÍA PREHISPÁNICA Y EUROPEA DE LA TABLETA DE METAL DEL MUSEO DE LA PLATA
}

\author{
REVEALING THE PREHISPANIC AND EUROPEAN ICONOGRAPHY \\ OF THE METAL TRAY FROM LA PLATA MUSEUM
}

Helena Horta ${ }^{a}$, Verónica lema ${ }^{B}$, María Teresa Plazac \& Carolina Odoned

Presentamos el análisis de la única tableta elaborada en metal hasta ahora conocida en el registro arqueológico Centro-Sur Andino (Museo de La Plata, Buenos Aires, Argentina) y reviste características peculiares en su manufactura y en su iconografía. Estos aspectos han sido abordados junto con la revisión de datos referidos a su procedencia, con el fin de interpretar su iconografía y dilucidar la posible ubicación temporal de su fabricación. Nuestro planteamiento es que su elaboración habría ocurrido en tiempos coloniales tempranos, no obstante, conservaría e incorporaría elementos de la imaginería prehispánica, en una inédita amalgama compuesta de rasgos andinos y europeos.

Palabras clave: Iconografía prehispánica, Cruz colonial andina, Tableta de inhalación, Metalurgia andina.

The present work deals with the analysis of the only metal tray known so far in the Andean Central-South archaeological record. This piece, which is part of the collection at the Museum of La Plata (Buenos Aires, Argentina), shows distinctive features both in its manufacture and in its iconography. These characteristics have been addressed together with the review of data regarding its origin, in order to interpret its iconography and elucidate the possible temporal location of its manufacture. We propose that its manufacture dates back to early colonial times; however, it would preserve and incorporate elements of pre-Hispanic imagery, in an unprecedented combination of Andean and European features.

Keywords: Pre-Hispanic Iconography, Andean Colonial Cross, Snuff Tray, Andean Metallurgy.

\section{INTRODUCCIÓN}

La tableta que aquí analizamos (fig. 1) forma actualmente parte de la colección Benjamín Muñiz Barreto del Museo de La Plata y lleva el número 1491. En la ficha correspondiente se lee: “Tableta de bronce con dos figuras antropomorfas en la parte superior, $150 \mathrm{~mm}$ de longitud, Pucará de Tilcara, Jujuy, Arg.. Considerando la historia de conformación de dicha colección (Balesta \& Zagorodny 2000, Arena 2008, Otero 2013) y la numeración asignada a la tableta en el primer cuaderno de registro de la colección, es probable que la misma corresponda a piezas que Muñiz Barreto comprara sueltas a otros individuos, o bien que formara parte de las obtenidas por Carlos Schuel, quien realizó sus tareas en la Provincia de Jujuy entre 1919 y 1920, financiado por Muñiz Barreto. Schuel no dejó un registro escrito prolífico ni detallado de sus hallazgos, los cuales fueron producto de excavaciones en la zona de quebrada y puna de la mencionada provincia (Krapovickas 1958-1959, Balesta \& Zagorodny 2000, Nielsen 2018).

A Helena Horta Tricallotis, Instituto de Investigaciones Arqueológicas y Museo R. P. Gustavo Le Paige s.j., San Pedro de Atacama, Universidad Católica del Norte, Chile. E-mail: hhorta@ucn.cl

B Verónica Soledad Lema, Instituto de Humanidades, Universidad Nacional de Córdoba-ConicET, Córdoba, Argentina. E-mail: vslema@hotmail.com

C María Teresa Plaza C., investigadora independiente. E-mail: tereplazacalonge@gmail.com

D María Carolina Odone, Instituto de Historia, Pontificia Universidad Católica de Chile, Santiago, Chile. E-mail: modoneco@uc.cl Recibido: enero 2019. Aceptado: mayo 2019. 

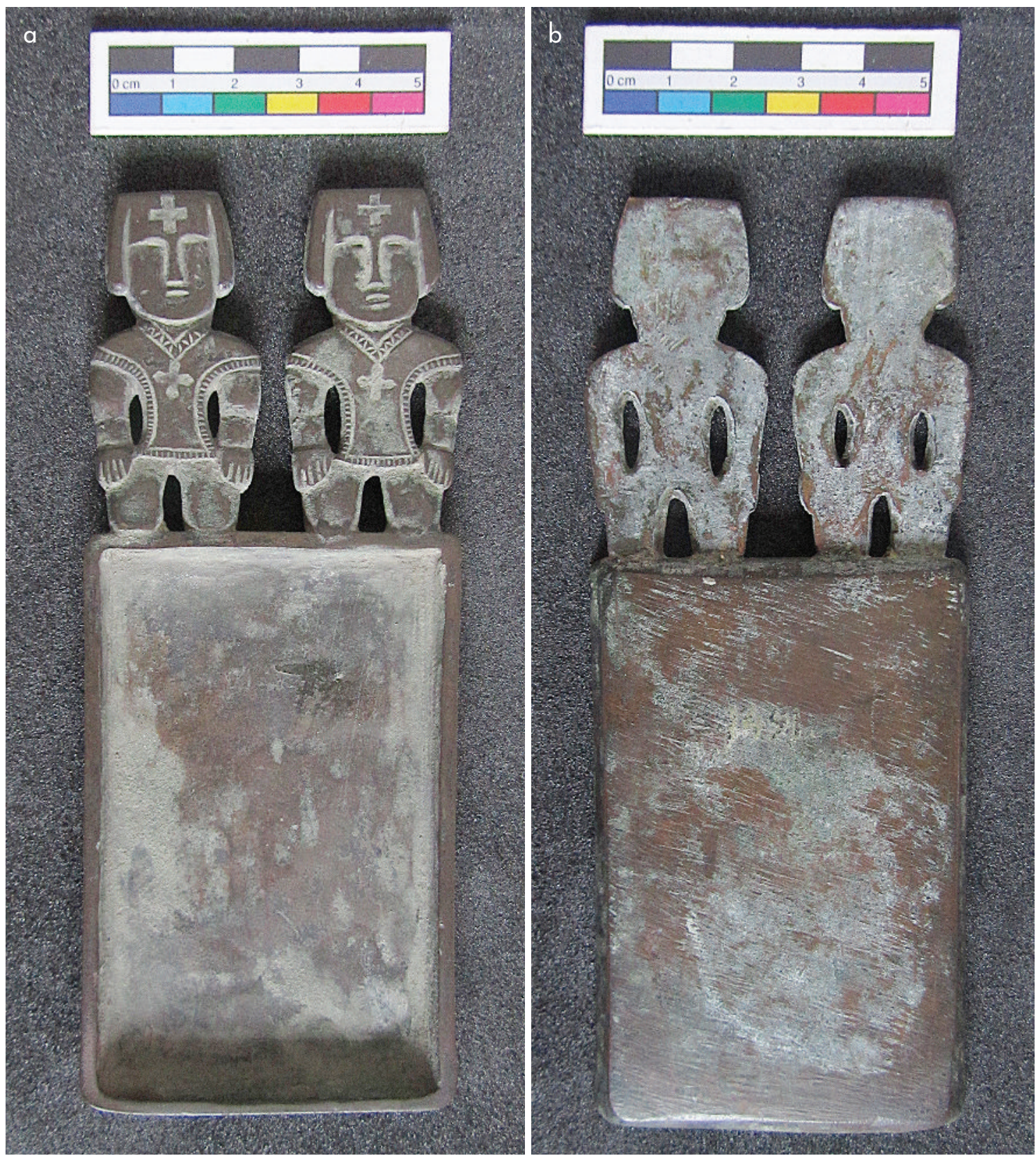

Figura 1 a-b: Anverso y reverso de la tableta de metal Nº 1491 de la colección Benjamín Muñiz Barreto procedente del Pucará de Tilcara, Jujuy, Argentina, del Museo de La Plata, Facultad de Ciencias Naturales y Museo de la Universidad Nacional de La Plata. (Fotografías: M.T. Plaza). Figure $1 \boldsymbol{a}$ - $b$ : Obverse and reverse of the metal tray $N^{\circ} 1491$ in the Benjamín Muñiz Barreto collection from the Pucará of Tilcara, Jujuy, Argentina, at La Plata Museum in the Faculty of Natural Sciences and the National University of La Plata Museum. (Photographs: M.T. Plaza).

El Pucará de Tilcara se ubica en las proximidades del actual poblado de Tilcara, al sur de la confluencia entre los ríos Grande de la Quebrada y Huasamayo, en el sector medio de la Quebrada de Humahuaca, Jujuy,
Argentina. Este sitio ha sido objeto de sucesivos estudios desde inicios del siglo xx y hoy se considera que cuenta con vestigios de ocupaciones que tuvieron lugar desde, al menos, ${ }^{1}$ el Período Tardío o de Desarrollos Regionales 
(ca. 900 DC), pasando por ocupaciones del Período Inkaico, hasta momentos de ocupación correspondientes al Período Hispano-Indígena (Debenedetti en Torres 1987, Casanova 1950, Zaburlín 2009, Gluzman 2010, Otero 2013, Zaburlín \& Otero 2014, entre otros). Para este último momento se registraron principalmente enterratorios en la zona cuspidal del Pucará de Tilcara, habiéndose hallado también enterratorios de igual cronología en el ejido del pueblo de Tilcara (como el cementerio de La Falda). En ambos casos se ha interpretado que se trataría de inhumaciones correspondientes a personas de elite (Zaburlín 2009).

Para los fines de este trabajo resultan particularmente interesantes los análisis realizados por Gluzman (2010) sobre placas metálicas de época de contacto, recuperadas en el Pucará de Tilcara, donde se conjugan elementos iconográficos prehispánicos en diálogo con otros de raigambre europea. Estas placas se encuentran también en el Museo de La Plata y pertenecen a la colección Schuel, incluida en la colección Muñiz Barreto. Gluzman afirma que "según A. González (1992: 77)", estos ejemplares "debieron ser hallados por la misma persona en un mismo sector del Pucará de Tilcara”, y propone que Schuel debió excavar una estructura o un grupo de estructuras próximas entre sí y pertenecientes a momentos de contacto hispano-indígena (Gluzman 2010: 64). La autora registra distintos motivos en estas placas, principalmente rostros antropomorfos, ofidios, volutas y motivos geométricos o lineales, elaborados en la mayoría de las placas mediante las técnicas de repujado e incisión, excepto en el caso de los ejemplares $\mathrm{N}^{\circ} 6793$ y 1338 que, como veremos más adelante, fueron confeccionados mayormente en cobre y mediante fundición. El ejemplar 1338 posee una contra argolla para su suspensión sugiriendo que se colgaba al cuello o cosía a la ropa. Siguiendo a González 1992, ${ }^{2}$ la autora considera que, en los restantes casos, varias de las piezas pudieron haber sido cosidas a estandartes o a la vestimenta. Al igual que lo mencionado para otros contextos hispano-indígenas del Pucará de Tilcara y del cementerio de La Falda en el actual pueblo de Tilcara, Gluzman plantea que estas placas metálicas habrían estado vinculadas a una suerte de "demostración" de status por parte de jefes étnicos locales con cierta preeminencia social.

De acuerdo con Torres (1987), además de la tableta que aquí nos ocupa y que fuera también mencionada por González (1977, fig. 328 en Torres 1987) y descrita por Raffino (1983: 191), en el Pucará de Tilcara se recuperaron tres tubos para inhalación y otras cuatro tabletas más, reportadas por Casanova (1950).

\section{ICONOGRAFÍA DE LA TABLETA DE METAL Y SUS RELACIONES ESTILÍSTICAS A NIVEL REGIONAL}

La tableta de metal de la figura 1 consta de dos personajes en posición frontal, erguidos sobre piernas y con los brazos a los costados hasta la altura de los muslos, pendiendo de forma tal que se aprecian los cinco dedos de las manos. La técnica de fabricación de la pieza dio como resultado un volumen bidimensional a los personajes y se utilizó el recurso del calado en el metal para conformar el espacio entre brazos/cuerpo y entre cada una de las piernas. Se trata de dos figuras humanas casi idénticas, con las cabezas sobredimensionadas respecto de los cuerpos y con piernas que no presentan pies. Las cabezas lucen probablemente gorros, sobre los cuales se aprecian cruces de lados iguales. Los rostros son redondos, con la señalización de las cejas arqueadas y las cavidades oculares unidas mediante una línea continua. Por debajo de las narices -delgadas y largas- se observan bocas ovaladas, mientras que no hay figuración de las orejas y los ojos mismos son señalados, al igual que las bocas y las cruces, por medio de leves depresiones en la superficie de metal. El tocado o cabello de los personajes los cubre hasta la altura de la nariz. Por su parte, la vestimenta de túnica es idéntica para ambas figuras y fue plasmada por medio de incisiones paralelas que representan el bordado de las costuras laterales de dichas prendas. El mismo recurso se aplicó para el borde inferior de las mismas, mientras que para la abertura del escote, el diseño consiste en una línea zigzag, lo cual genera la posibilidad de que se tratase de una gargantilla y no de parte de la prenda de vestir. Inmediatamente por debajo de los escotes o gargantillas se ubican cruces de extremos aguzados o romboides, diferentes a las cruces que se observan en la frente de las figuras humanas. Por sobre las manos se aprecia una línea que parece indicar el borde de probables brazaletes en las muñecas de los personajes.

Aparte de esta tableta de metal, en su trabajo de 1987 Torres menciona otras dos tabletas de madera que también poseen dos personajes yuxtapuestos con cruces en la frente, las cuales serían insignias en gorros 


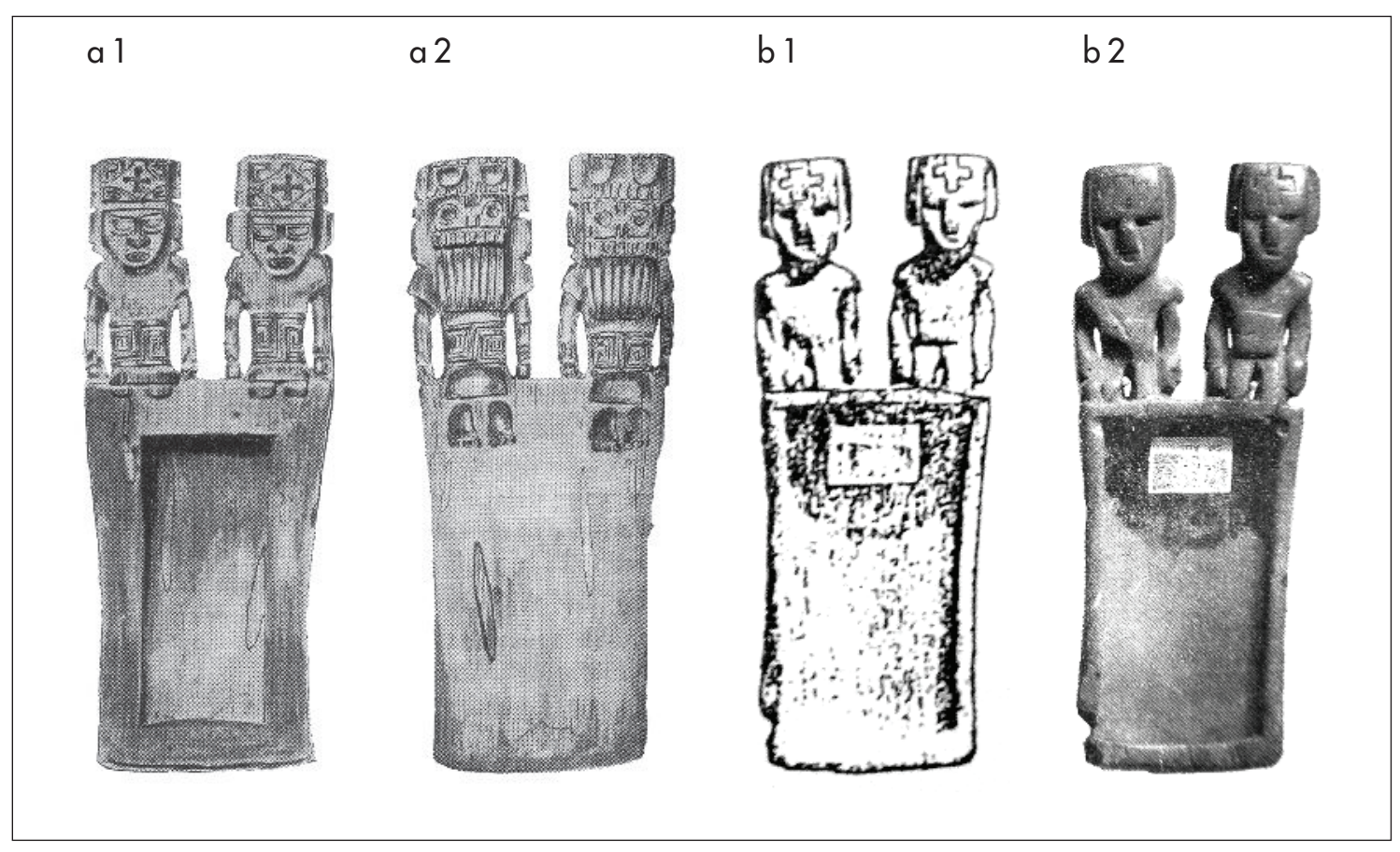

Figura 2. Tabletas para inhalar de estilo Circumpuneño presentando elementos iconográficos compartidos con la tableta de metal de Tilcara: 2a) ejemplar de Chiuchiu (tomado de Oyarzún 1931); 2b1) dibujo del ejemplar de La Rinconada (tomado de Torres 1987); 2b2) foto del ejemplar de La Rinconada (tomada de Von Rosen 1924). Figure 2. Circumpuneño style snuff trays showing iconographic features shared with the Tilcara metal tray: 2a) Chiuchiu specimen (taken from Oyarzún 1931); 2b1) drawing of La Rinconada specimen (taken from Torres 1987); 2b2) photograph of La Rinconada specimen (taken from Von Rosen 1924).

o tocados. Una procede de Chiuchiu, norte de Chile (fig. 2a, Oyarzún 1937, Torres 1987: fig. 52) y la otra del Pucará de Rinconada, ubicado en la Quebrada de Humahuaca con una cronología correspondiente a momentos tardíos-inkaicos (fig. 2b, Torres 1987: fig. 156). Una imagen de frente y dorso de esta última tableta fue publicada por Ambrosetti (1902) y por Rosen (1924). Lamentablemente, ninguna de estas dos piezas se encuentra disponible para su consulta en la actualidad, por lo cual solo contamos con las imágenes extraídas de la bibliografía existente. Aun así, en base a paralelos iconográficos establecidos en la revisión de una muestra amplia de parafernalia adscrita al estilo Circumpuneño (Horta 2012, 2018), podemos establecer que, tanto en la tableta de Chiuchiu como en la de La Rinconada, se representó a sacrificadores, aunque ello no resulte explícito a primera vista.

Los personajes de la tableta de Chiuchiu están ataviados con la vestimenta propia de su rol, la cual incluye túnica, gorro con cruz de lados iguales y faja con diseño de greca. Al mismo tiempo, se encuentran arrodillados, tal como lo exigía la puesta en escena propia de dicho estilo. El dibujo sobre esta pieza (Oyarzún 1931), desgraciadamente no es suficientemente claro como para colegir la presencia de los instrumentos de la decapitación, cuestión que sí es posible en el caso de la tableta de La Rinconada. En la foto que disponemos de esta última (fig. 2b2) se aprecian dos personajes igualmente arrodillados, con abultamientos distintos entre lo que es sostenido por cada mano. Esto ha sido registrado en otros casos del estilo Circumpuneño, a saber, volumen circular para la cabeza cortada en la mano izquierda y volumen oblongo para el hacha en la mano derecha. Adicionalmente, en la pieza de La Rinconada se observa el uso de faja sobre la túnica, aunque no se aprecia su diseño. En suma, en ambas tabletas nos encontramos frente a la figura doble de El Sacrificador, en su versión conocida para Atacama y el noroeste de Argentina, durante el Período Intermedio Tardío y Tardío (ca. 1000-1500 DC).

En relación con otras piezas del estilo Circumpuneño, estos personajes y sus tocados se asemejan a 


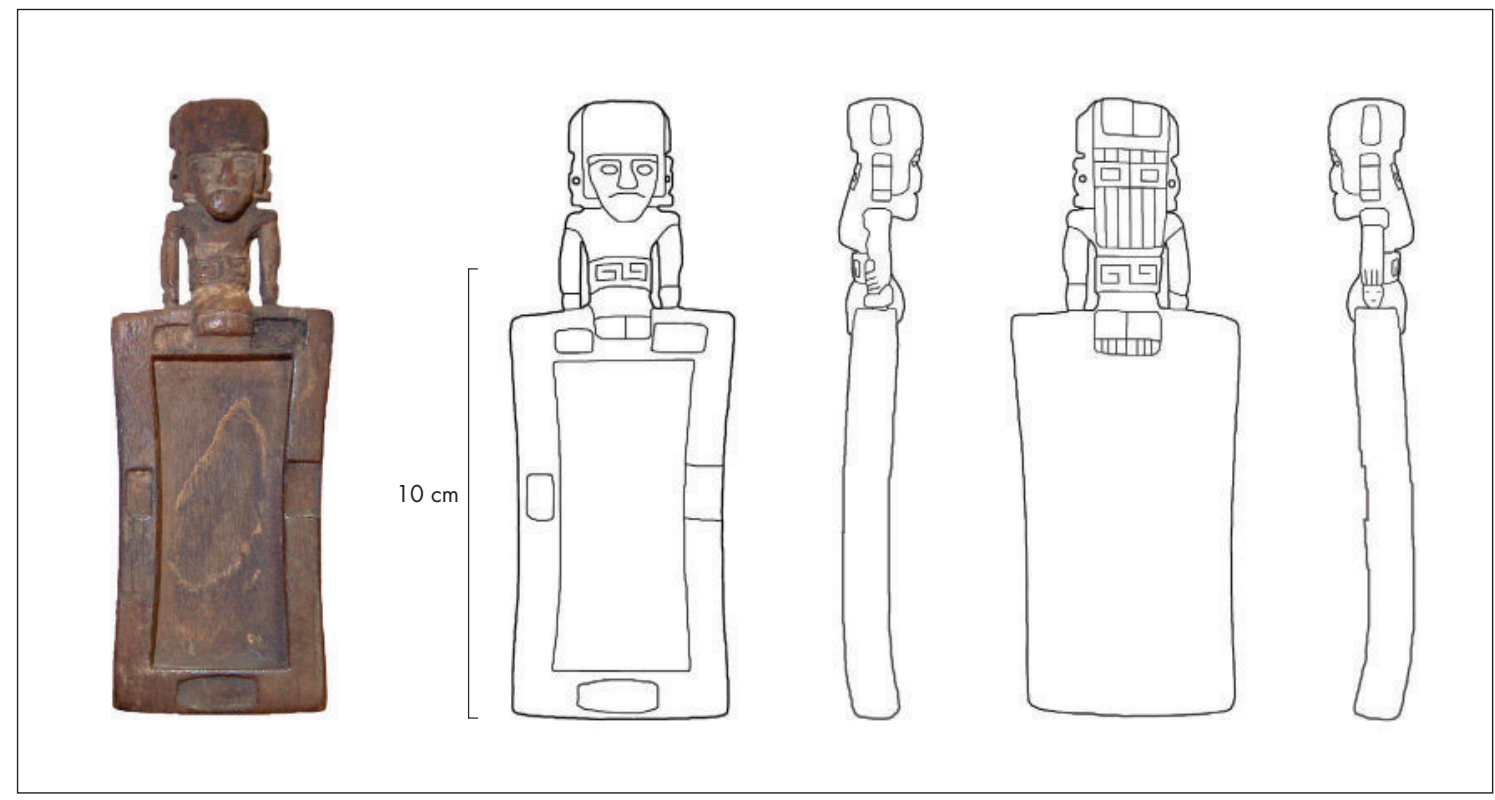

Figura 3. Tableta sin procedencia conocida con personaje sacrificador del estilo Circumpuneño (colección Museo Chileno de Arte Precolombino. Horta 2012: fig. 9). Figure 3. Tray of unknown origin showing a sacrificer character of the Circumpuneño style (Chilean Museum of Pre-Columbian Art collection. Horta 2012: fig. 9).

los de la tableta sin procedencia publicada por Horta (2012, fig. 9; aquí fig. 3). Si bien, el personaje de esta última tableta es solo uno y no lleva la insignia en forma de cruz, en sus otros aspectos, tales como portar en las manos los elementos de la decapitación (hacha y cabeza cortada), poseer faja con grecas y encontrarse arrodillado, se asemeja tanto a los personajes de la tableta de Chiuchiu como a los del Pucará de La Rinconada.

\section{La tableta de La Rinconada y su estrecha semejanza con la de metal}

La tableta de La Rinconada merece una mención aparte, ya que con los rasgos propios del estilo Circumpuneño (figs. $2 \mathrm{~b} 1$ y 2b2), ofrece un paralelo iconográfico que resulta extraordinariamente estrecho. Tanto la de metal como la de madera comparten una iconografía similar, basada en dos personajes humanos sin características felínicas ni máscaras que aludan al felino, con vestimenta especial (túnica, tocado con cruz de lados iguales, o en su defecto pelo corto, sobre el cual se habría dispuesto la insignia en forma de cruz). ${ }^{3}$ Sin embargo, las diferencias que podemos apreciar entre la tableta de metal y la de madera, son notorias y se relacionan básicamente con: a) la postura corporal: en el ejemplar del Pucará de Tilcara, como ya se ha mencionado, se observa a los personajes erguidos en dos piernas cubiertas probablemente por un calzón, lo cual hace que se angosten levemente hacia su unión con la cavidad de la tableta. Por su parte, la tableta del Pucará de La Rinconada los presenta arrodillados, por lo que las piernas, en lugar de angostarse, se ensanchan levemente hacia la unión con la cavidad de la tableta;

b) el carácter bidimensional: en el ejemplar de metal los personajes no presentan detalles en su parte posterior (fig. 1b), mientras que la tableta de madera es tridimensional;

c) en la tableta de La Rinconada se aprecia la condición de sacrificadores de los personajes mediante la representación del hacha y la cabeza cortada que sostienen en las manos. Por el contrario, los personajes de la tableta de Tilcara tienen las manos desprovistas de cualquier elemento. Además, los brazos están orientados hacia el frente del cuerpo y no hacia los lados como en la tableta de madera;

d) las dos tabletas comparten el uso de la cruz de lados iguales, pero no la cruz de extremos aguzados o romboides, insignia ausente en la del Pucará de La Rinconada; 


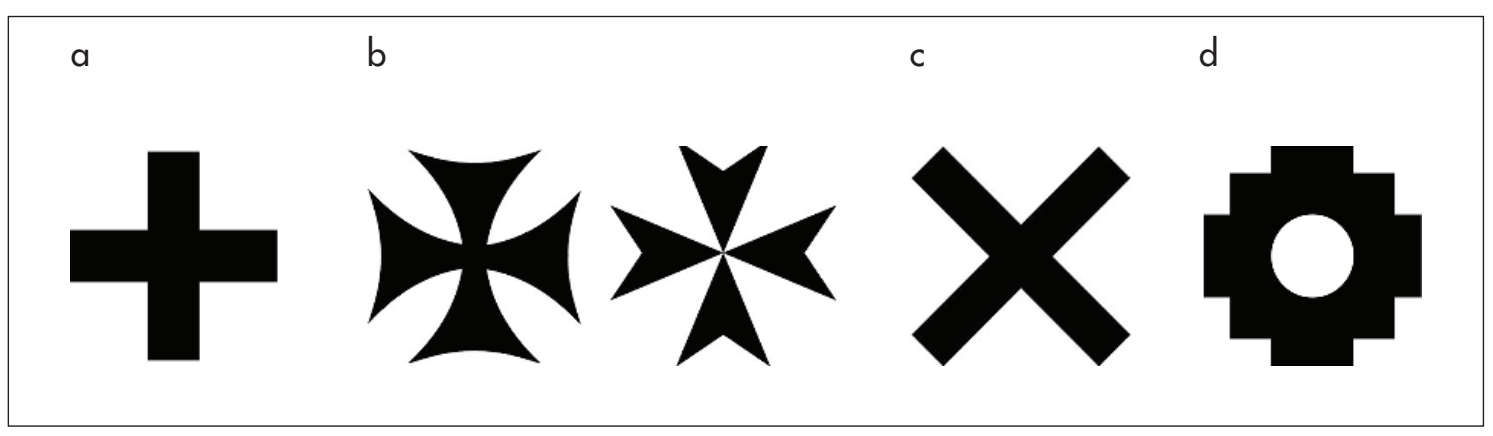

Figura 4. Diferentes tipos de cruces de la época prehispánica (según Quiroga 1898 y 1901): a) cruz griega; b) cruces de Malta; c) cruz de San Andrés; d) chacana. Figure 4. Different types of crosses from the pre-Hispanic era (according to Quiroga 1898 and 1901): a) Greek cross; $b$ ) Maltese crosses; c) Saint Andrews cross; d) chakana.

e) la faja de los sacrificadores circumpuneños de la tableta de La Rinconada se encuentra ausente en la indumentaria de los personajes de Tilcara;

f) en la tableta de La Rinconada (fig. 2b2), al igual que en otras del estilo Circumpuneño, no ha sido registrada la representación de la costura lateral de las túnicas, a pesar de que en el registro arqueológico la exhiben y era realzada mediante bordados polícromos, tanto en tiempos preincaicos como durante el incanato. Esto denota un cambio importante y constituye un detalle de la tableta de metal que trataremos más adelante.

g) la representación de figuras gemelas o de carácter dual (sensu González 1998) no está presente solo en la parafernalia circumpuneña, sino que también se observa en los discos y placas de metal del noroeste de Argentina.

\section{ANTECEDENTES SOBRE CRUCES EN LOS ANDES CENTRO-SUR}

En su libro La cruz en América, publicado en 1901, Adán Quiroga hace un exhaustivo compendio de las cruces presentes en piezas cerámicas y en diversos soportes correspondientes a momentos prehispánicos de América (arte rupestre, metalurgia, entre otros), junto con datos folklóricos vinculados al tema, poniendo especial énfasis en el noroeste de Argentina, particularmente en el área denominada "Calchaquî" (correspondiente a los Valles Calchaquíes) y en las cerámicas de estilo Santa María, San José y Belén, correspondientes al Período de Desarrollos Regionales. En dicho trabajo, al igual que en uno anterior de 1898 sobre el mismo tema, registra la presencia prehispánica de cruces griegas o de lados iguales (fig. 4a), de Malta (fig. 4b), de San Andrés (fig. 4c) y andinas o chacanas (fig. 4d), incluyendo cruces de lados iguales dentro de campos cruciformes, lo cual el autor denomina "cruces dobles".

Respecto de la cruz de lados iguales o cruz griega (fig. 5), contamos con múltiples evidencias del Norte Grande de Chile, desde prendas textiles del Formativo (Sinclaire 1997, Horta 2004), hasta petroglifos, geoglifos y otros soportes del Período Intermedio Tardío (Berenguer 2004), al igual que múltiples casos en diversas zonas del noroeste argentino (Ambrosetti 1908). El caso del casco en técnica de cestería (fig. 5b) merece mención especial, ya que se perfila como símbolo identitario del complejo Pica-Tarapacá. Recientemente, Pacheco y colaboradores publicaron un recuento de 15 casos conocidos para el Norte Grande de Chile, de los cuales al menos seis presentan la cruz de lados iguales como diseño destacado (Pacheco et al. 2016: figs. 2-3).

A estas clasificaciones previas proponemos sumar, como una variante de la cruz maltesa o de Malta, la que denominamos "cruz de aspas" (fig. 6), ya que presenta alta frecuencia en los discos y placas rectangulares del noroeste argentino durante el Período de Desarrollos Regionales, así como también en otros soportes arqueológicos del Centro-Sur Andino.

En cuanto a las cruces de momentos coloniales presentes en contextos indígenas, las que veremos más adelante en detalle, la cruz de Carabuco ilustrada por Guaman Poma es una cruz de vástago superior corto, usada con fines evangelizadores en los Andes entre fines del siglo xvi y comienzos del xvir según Arenas (2011), quien la registra en el sito Toro Muerto ubicado en la IV Región de Coquimbo, Chile, junto a otras representaciones rupestres coloniales. Este autor, siguiendo a 
a

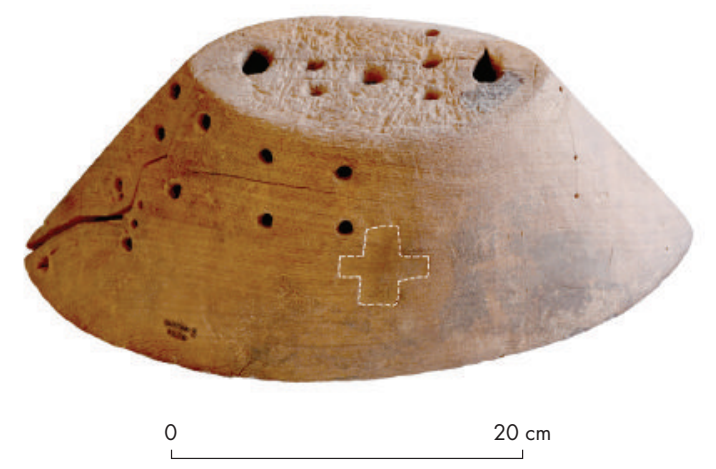

C

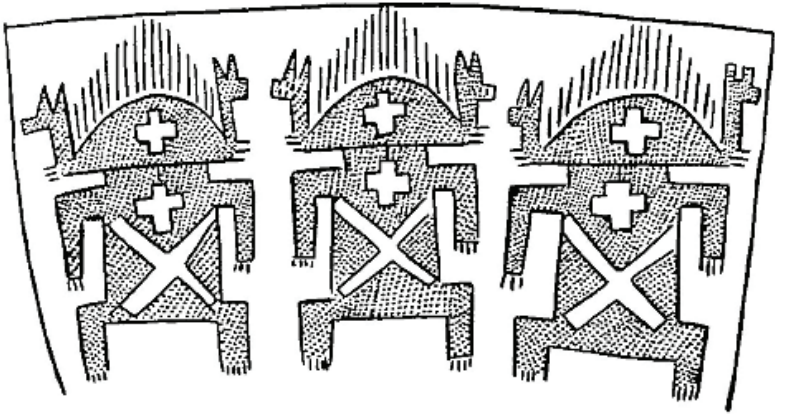

$d$

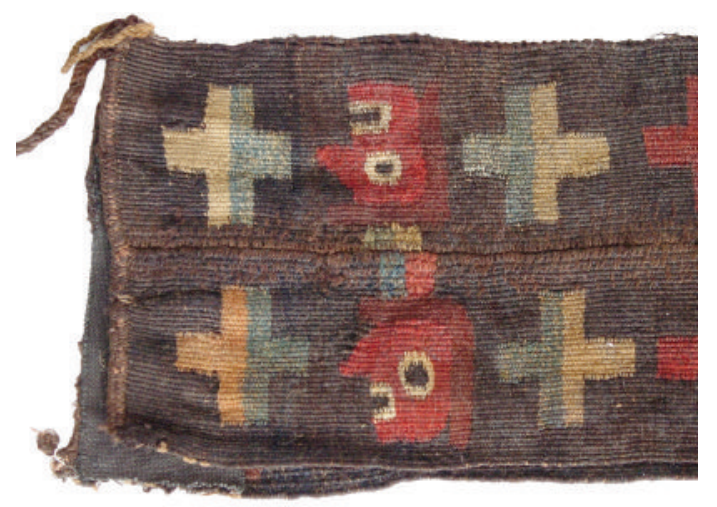

b
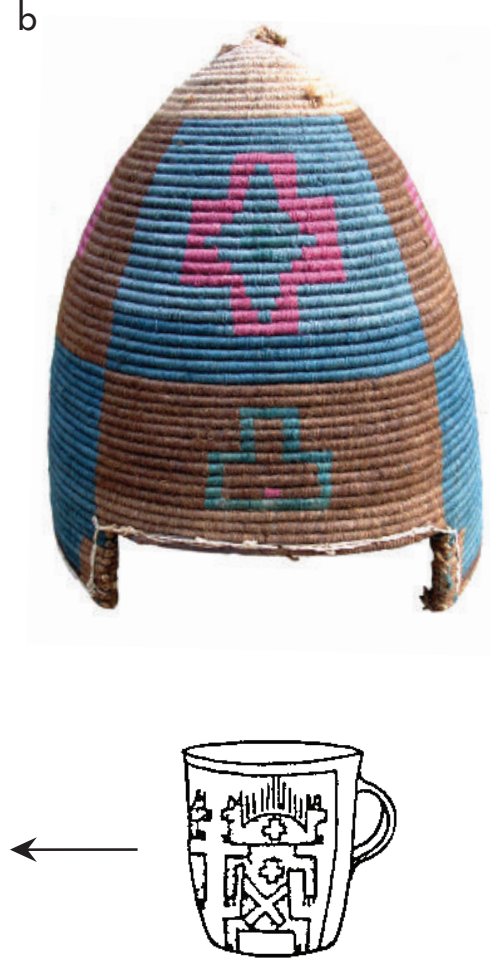

e



Figura 5. Ejemplos del uso de la cruz griega o de lados iguales en artefactos prehispánicos del área Centro-Sur Andina: a) campana de madera de la tumba 3236-38 del cementerio Quitor 9 con señalización digital del lugar ocupado por la cruz. (Fotografía: H. Horta, colección IAAM/UCN); b) "casco" en técnica de cestería, sin contexto (fotografía: H. Horta, colección Museo Regional de Iquique, Chile); c) cerámica La Ciénaga (González 1972: fig. 8); d) textil reutilizado como deformador craneano del cementerio de Azapa 70 (Horta 2004: fig. 9a), colección Museo Arqueológico San Miguel de Azapa, Universidad de Tarapacá, Arica; e) urna santamariana de colección Quiroga (tomado de Posnansky 1945: plancha LXI). Figure 5. Instances of the use of the Greek cross or cross of even sides in pre-Hispanic artefacts of the Central-South Andean area: a) wooden bell from grave 3236-38 at Quitor 9 cemetery with digital signaling of the place of the cross. (Photograph: H. Horta, IAAM/UCN collection); b) basketwork "helmet", without context (photograph: H. Horta, Regional Museum of Iquique collection, Chile); c) La Ciénaga ceramic (González 1972: fig. 8); d) textile reused as cranial deformer from the Azapa 70 cemetery (Horta 2004: fig. 9a), Archaeological Museum San Miguel de Azapa collection, University of Tarapaca, Arica; e) Santa María urn from the Quiroga collection (taken from Posnansky 1945: sheet LXI). 


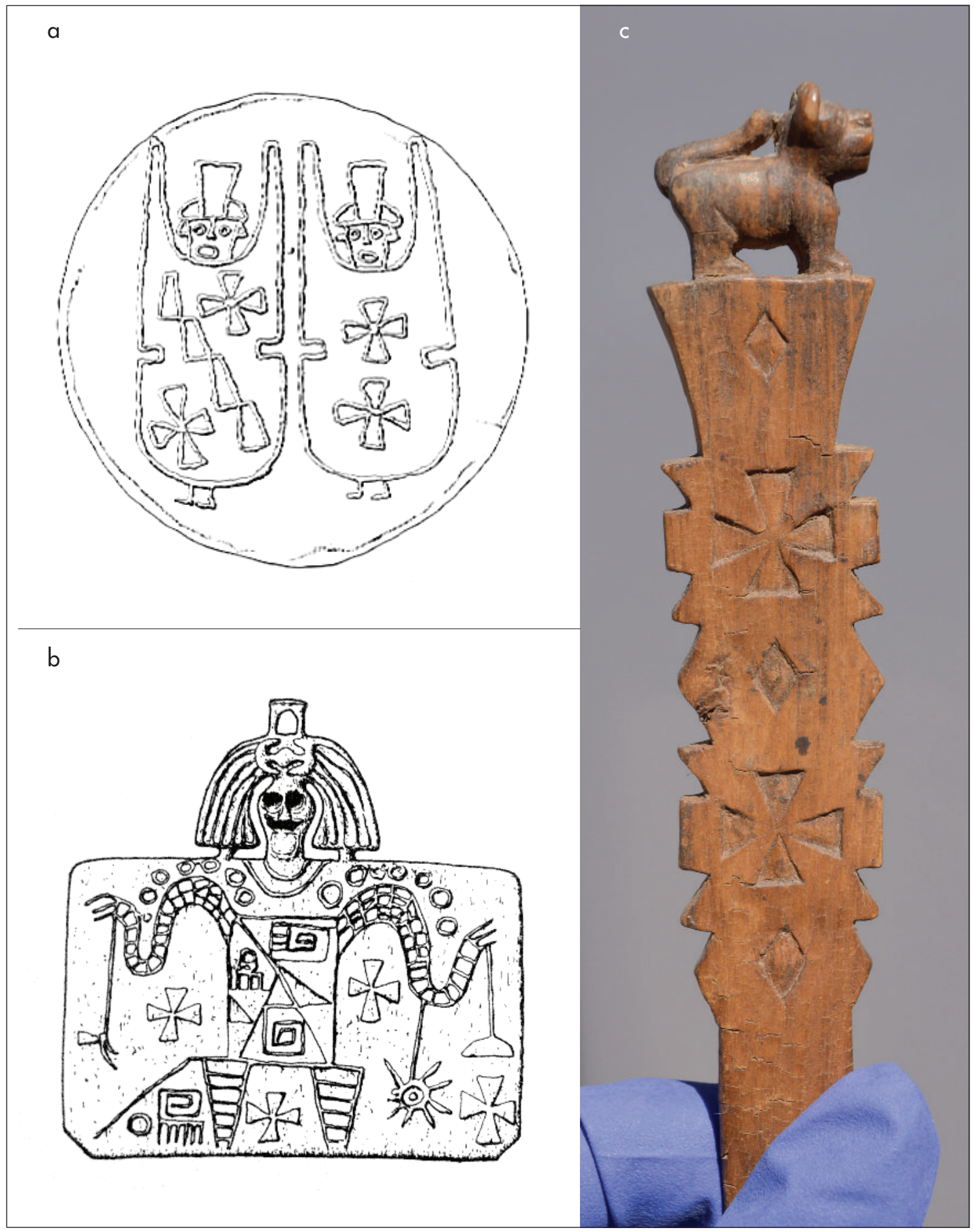

Figura 6. Cruz de aspas presente en: a) un disco procedente de Cachi, Noroeste Argentino (Mayer 1986: lám. 31); b) una placa del Noroeste Argentino (Mayer 1986: lám. 84); c) en el mango de cuchara de madera (fragmentada) de la tumba 3671 del cementerio Quitor 6, San Pedro de Atacama. (Fotografía: H. Horta, colección IAAM/UCN). Figure 6. Cross of blades present on: a) a disc from Cachi, Argentine Northwest (Mayer 1986: plate 31); b) a sheet from the Argentine Northwest (Mayer 1986: plate 84); c) wooden spoon handle (broken) from grave 3671 of Quitor 6 cemetery, San Pedro de Atacama. (Photograph: H. Horta, IAAM/UCN collection). 


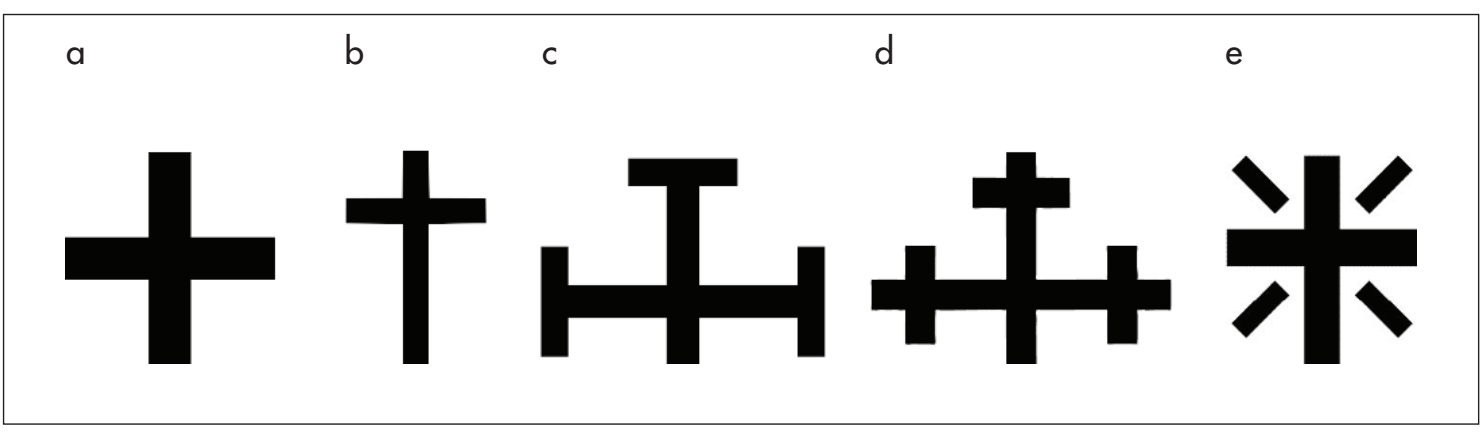

Figura 7. Cruces coloniales del área Centro-Sur Andina: a) cruz latina; b) cruz del calvario; c) cruz potenciada; d) cruz recruzada; e) cruz radiada. Figure 7. Colonial crosses of the Central-South Andean area: $\boldsymbol{a}$ ) Latin cross; $\boldsymbol{b}$ ) cross of Calvary; ) cross potent; $d$ ) cross crosslet; e) radiated cross.

Hosting (2004) quien realiza sus trabajos en la provincia de Espinar al sur de Perú, señala que las cruces coloniales registradas son variaciones de la cristiana o latina (fig. 7a), siendo la principal la cruz del calvario (fig. 7b) cuyo pedestal puede variar siendo escalonado, cónico o triangular, entre otros- y otras variaciones frecuentes como la cruz potenzada o potenciada (fig. 7c), la cruz recruzada (fig. 7d) y la cruz radiada o iluminada (fig. 7e). Estos mismos tipos de cruces han sido registrados como motivos rupestres grabados o pintados correspondientes a momentos coloniales por Strecker (1992), Taboada (1992), Martínez (2009), Arenas (2011), Arenas y Odone (2015), Blanco et al. (2015) para distintas regiones de Chile, por Cruz (2006) para el departamento de Potosí y en regiones de Chuquisaca, Oruro y Pacajes, en Bolivia, y por Rivet (2013) para la puna jujeña de Argentina.

A los registros previos sobre soportes arqueológicos, podemos sumar las cruces que se registran en piezas del sitio Chañar Yaco, en la provincia de Catamarca, Argentina. Lafone Quevedo (1892) excavó cinco tumbas en dicho sitio, tras lo cual las piezas pasaron a formar parte de las colecciones del Museo de La Plata. De las cinco tumbas se recuperaron dos aribaloides, uno de ellos (fig. 8), posee motivos de cruces y en general su composición estilística remite a la influencia de elementos hispánicos (Moralejo 2010). Estas cruces no coinciden plenamente con las antes enumeradas (fig. 7a-d), por lo cual hemos decidido denominarla "cruz de extremos expandidos".

Pasando a los registros gráficos en papel, la obra Nueva Corónica y Buen Gobierno de Felipe Guaman Poma de Ayala (1615) ofrece un compendio muy rico, amplio y contundente para momentos tempranos posteriores a la Conquista. Las imágenes de Guaman Poma presentan numerosas escenas que involucran cruces. En algunas ocasiones ello ocurre de forma explícita y en otras aparecen apenas insinuadas. Un tipo de cruz conspicua en las representaciones es una variante que incorpora círculos en los extremos (la denominada "cruz pometada"), ${ }^{4}$ la cual está presente en los crucifijos y rosarios sostenidos en las manos por indígenas evangelizados (fig. 9a), asociadas a personajes del mundo hispano criollo colonial, sea en sus manos (fig. 9b) o colgando de sus cuellos (fig. 9c), en estandartes, escudos, coronas $\mathrm{y}$ techos de iglesias (fig. 9d).

En Guaman Poma vemos además la ya mencionada cruz de Carabuco (fig. 10a), junto al Apóstol San Bartolomé. En dicha lámina puede verse por sobre la cabeza del indio colla a punto de ser bautizado, una cruz maltesa o de aspas. Una cruz latina se observa en el pecho de Santiago Mataindios y pometada en el extremo de su estandarte (fig. 10b), a la vez que cruces griegas son exhibidas en las andas del inka (fig. 10c). Un recorrido preliminar por las imágenes de este cronista sugiere una división entre cruces asociadas a la acción evangelizadora y a los símbolos del poder hispano (latina, de Carabuco, pometada), y otras que se asocian exclusivamente al mundo andino indígena colonial (cruz maltesa o de aspas, cruz griega).

Entre las cruces asociadas específicamente a santos y/o apóstoles, podemos mencionar la cruz de Santiago (fig. 11a), conformada a partir de una espada en el eje vertical y aderezada con flores de lis en el eje horizontal. Una simplificación de esta cruz es la cruz de Santo Tomás o florenzada (fig. 11b), así llamada debido a que sus extremos presentan la forma de flor de lis.

Considerando lo anterior nos abocamos a la búsqueda de representaciones de Santiago presentes en cuadros, retablos y otros elementos de parafernalia 


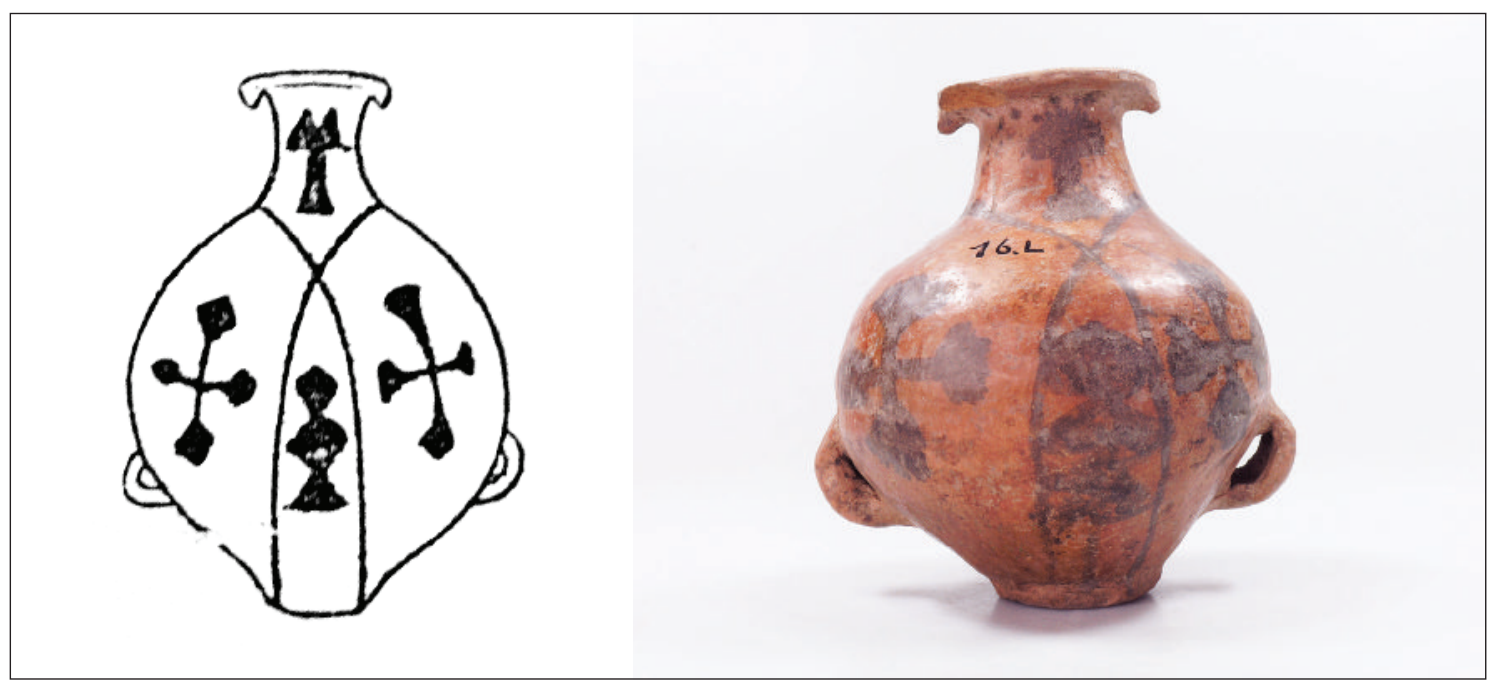

Figura 8. "Cruz de extremos expandidos" en aribaloide $N^{\circ} 4518$ del sitio Chañar Yaco: a) dibujo tomado de Lafone Quevedo (1892: 37, fig. 2f); b) foto gentileza de R. Moralejo. Figure 8. "Cross with expanded ends" on aribaloid jug $N^{\circ} 4518$ of the site Chañar Yaco: a) drawing taken from Lafone Quevedo (1892: 37, fig. 2f); $\boldsymbol{b}$ ) photograph courtesy of R. Moralejo.

religiosa que pudieran haber estado circulando en los inicios de la colonia en el ámbito surandino. La bibliografía analizada (Sanfuentes 2008, 2016; von Brunn 2009) nos ha permitido apreciar la representación de la cruz de San Santiago en el pecho del mismo, en la capa que porta sobre la túnica, o en su escudo ya sea en cuadros o imágenes de bulto a partir del siglo xvII sin que pudiésemos hallar registros previos (fig. 12).

Resumiendo los antecedentes sobre cruces prehispánicas y coloniales en el área andina centro sur podemos señalar que las cruces de extremos aguzados que poseen los personajes de la tableta de metal en el pecho no poseen un paralelo exacto en ningún otro soporte pre o post contacto. Además de la aparición de la cruz latina, la modificación en los extremos -y no en los brazosde las cruces es notoria durante momentos coloniales, los testimonios gráficos de Guaman Poma con la cruz pometada asociada a indios cristianizados y los símbolos de poder de los conquistadores es contundente a este respecto, sumándose las cruces de extremos expandidos de Chañar Yaco y las cruces recruzadas, potenzadas y florenzadas registradas en diversos soportes.

Con todo esto podemos proponer que las cruces griegas de la frente de los personajes poseen una clara presencia prehispánica que sobrevive luego del contacto, en tanto las cruces de extremos aguzados o romboides que exhiben en el pecho, a pesar de su carácter único, resultan ser más afines a las cruces que comienzan a registrarse luego de la Conquista, donde hay una tendencia particular a marcar distintas formas en los extremos de los brazos.

\section{La vestimenta de los personajes de la tableta de metal}

Desde la vestimenta también encontramos punto de apoyo para nuestro planteamiento acerca del carácter post-hispánico de la tableta que estamos analizando. Una lámina de Guaman Poma da testimonio de detalles de la vestimenta colonial que se encuentran en consonancia con la representación de las túnicas de los personajes de la tableta de Tilcara (fig. 13a). En esta última se ofrece la estampa de un "caballero segunda persona" con túnica sobrepuesta a calzón o calza-braga ancho, además de sombrero y botas a la usanza española.

Resulta notable en la túnica de este personaje la representación de las terminaciones bordadas del contorno de la prenda, incluyendo igualmente el adorno del escote. También hay que hacer notar el acinturamiento semejante de la figura.

Es en base a esta imagen del "caballero" que planteamos la posibilidad de que los personajes gemelos de la tableta hayan sido representados con una vestimenta similar, compuesta por túnica prehispánica y calzón español, ya que en ambos casos el uncu solo llega hasta la entrepierna. Igualmente, el inusual volumen de muslos y 


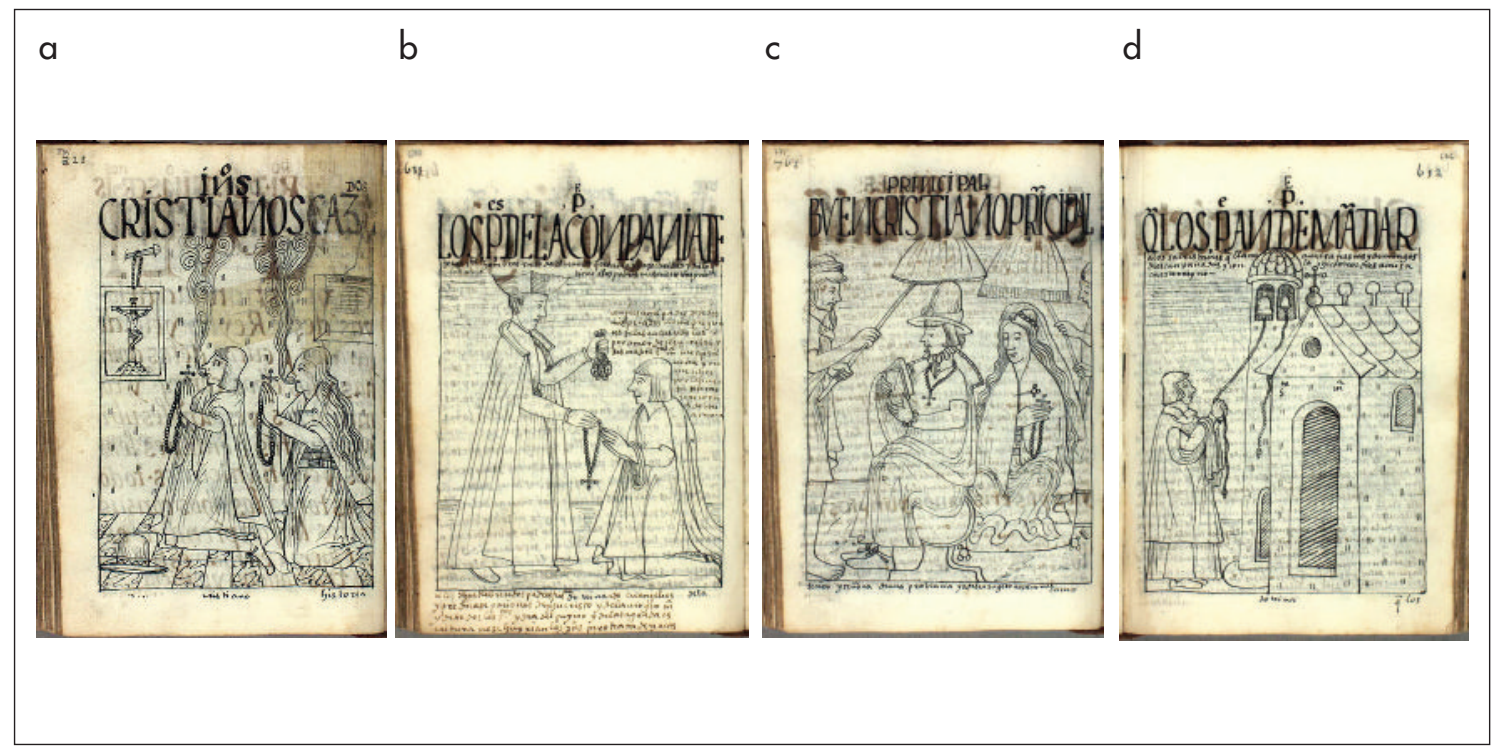

Figura 9. Cruz pometada en: a) lámina 835 "Los cristianizados”; b) lámina 649 “Los padres de la Compañía de Jesús"; c) lámina 775 "Cristianos ejemplares"; d) lámina 666 "El sacristán llama a los feligreses a misa" (tomado de Guaman Poma de Ayala 1615). Figure 9. Cross pommé on: a) sheet 835 "the Christianized"; b) sheet 649 "The fathers of the Society of Jesus"; $c$ ) sheet 775 "Exemplary Christians"; d) sheet 666 "The sacristan summoning parishioners to mass" (taken from Guaman Poma de Ayala 1615).

a

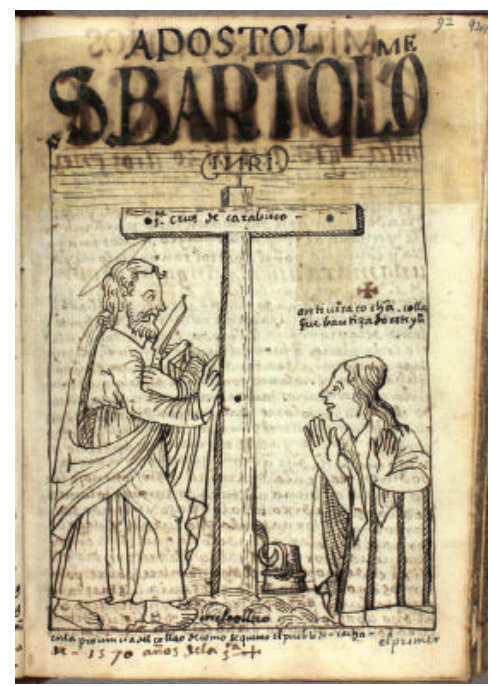

b

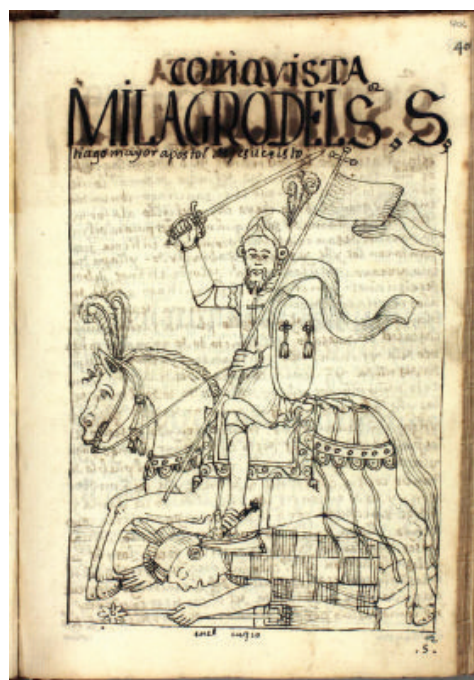



Figura 10: a) lámina 92 "Apóstol San Bartolomé”; b) lámina 406 “Santiago Mayor, Apóstol de Cristo, interviene en la guerra en el Cuzco"; c) lámina 333 "Las andas de piedras preciosas del Ynga, qhispi rampa" (tomado de Guaman Poma de Ayala 1615). Figure 10: a) sheet 92 "Saint Bartholomew the Apostle"; b) sheet 406 "Saint James the Greater, Apostle of Christ", intervenes in the war in Cuzco; $c$ ) sheet 333 "The Inka's litter of precious stones, qhispi rampa (taken from Guaman Poma de Ayala 1615). 


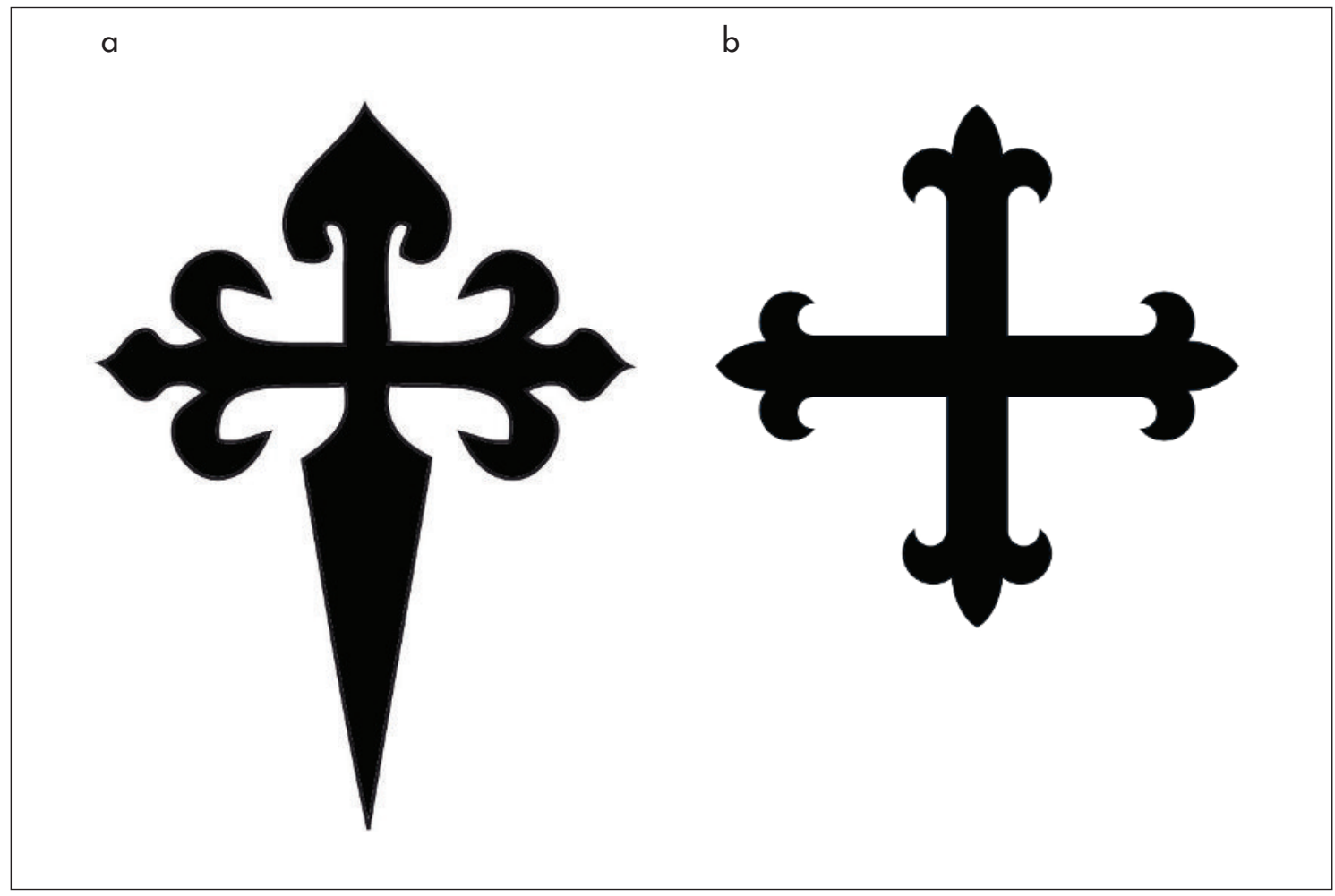

Figura 11: a) cruz de San Santiago; b) cruz de Santo Tomás o florenzada. Figure 11: a) cross of Saint James; b) Saint Thomas cross or cross fleury.
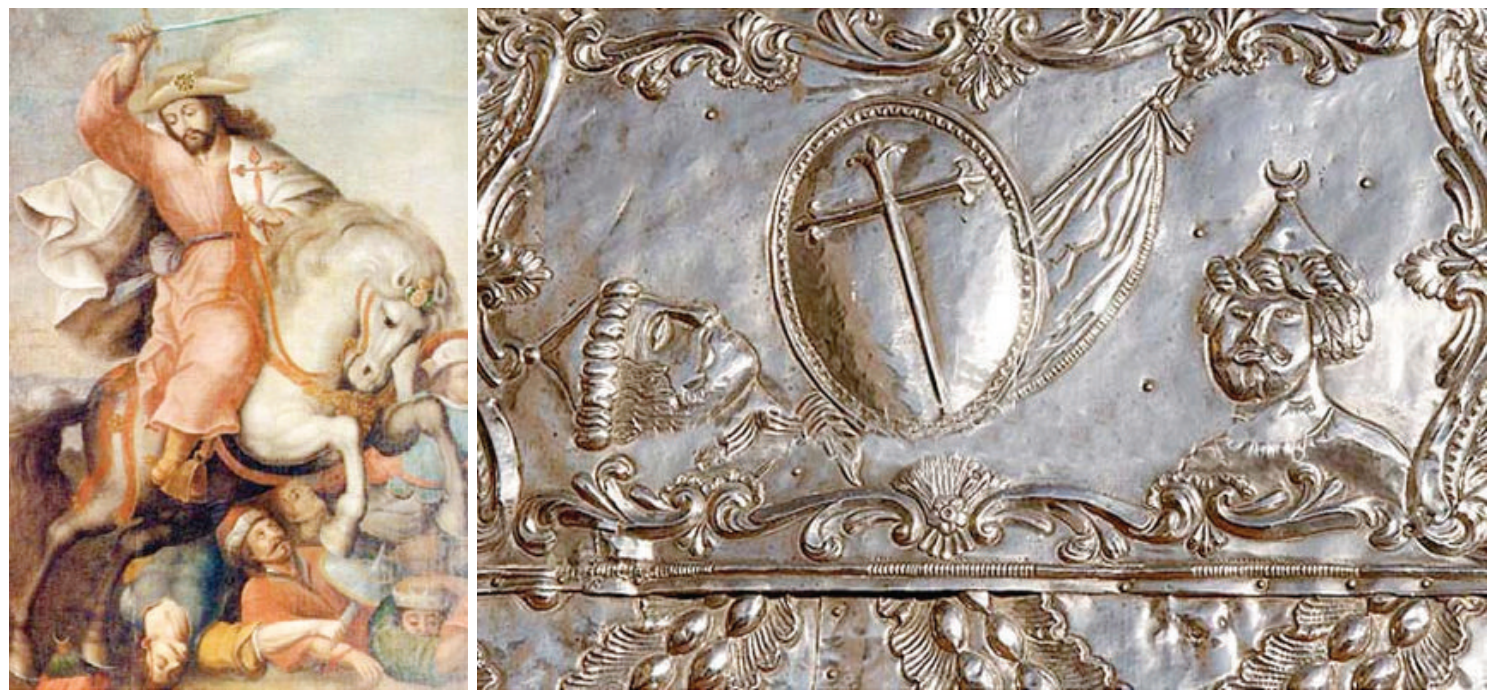

Figura 12: a) cruz de San Santiago (óleo sobre lienzo atribuido a Leonardo Flores, 1680. Colección Durán-Vázquez. La Paz/Bolivia. Tomado de Von Brunn 2009: 246); b) cruz florenzada (detalle del anda procesional de Cusco con un moro decapitado bajo el escudo con la cruz y otra cabeza de moro erguida. Tomado de Von Brunn 2009: 238). Figure 12: a) cross of Saint James (oil on canvas attributed to Leonardo Flores, 1680. Durán-Vázquez collection. La Paz/Bolivia. Taken from Von Brunn 2009: 246); b) Cross fleury (detail of the processional litter of Cuzco with beheaded Moor under the shield with the cross and another head upright. 

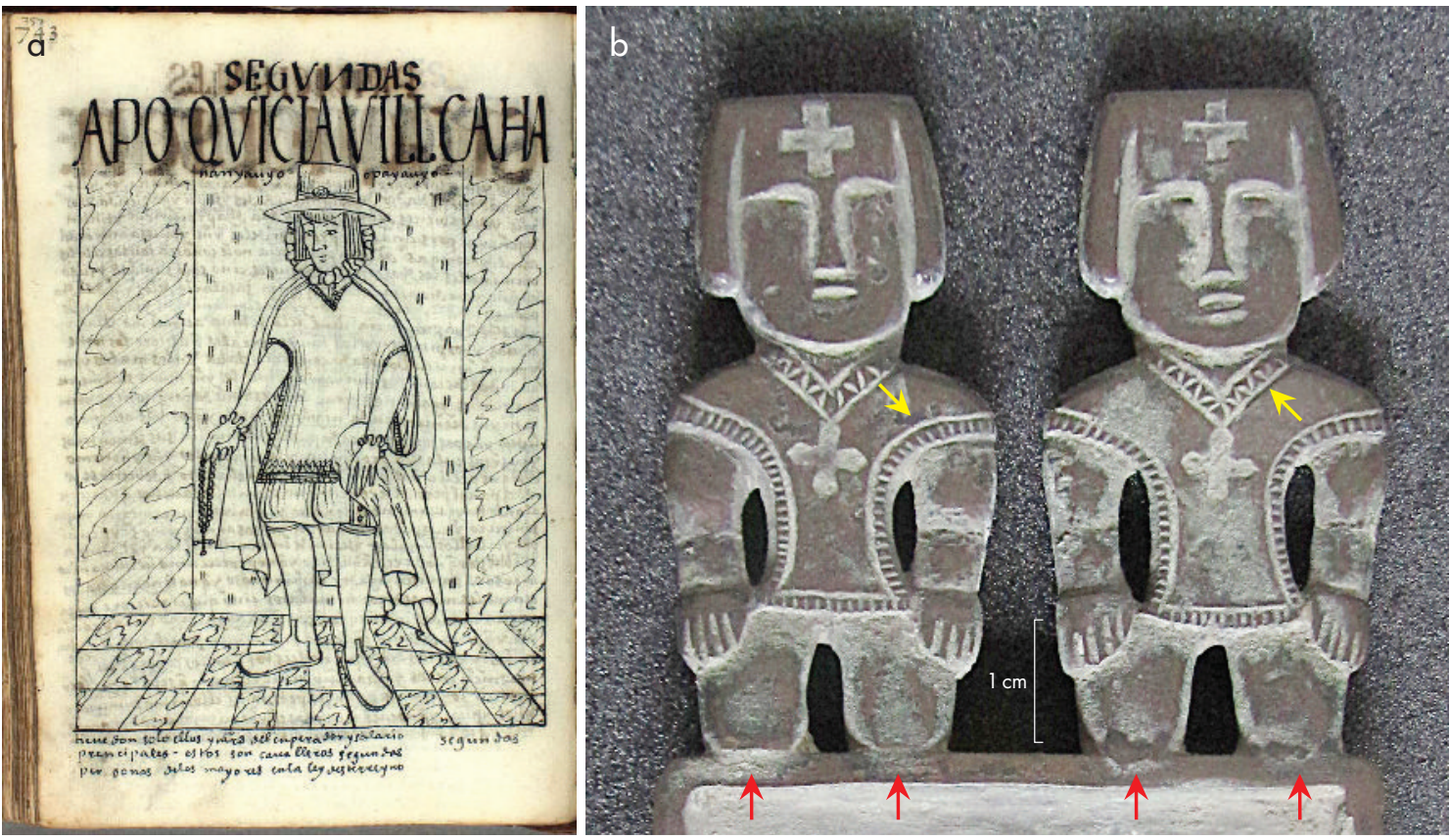

Figura 13: a) lámina 757 "Quicia Uillca, apu, señor principal del linaje de los Yauyos que tiene don y merced del emperador" (tomado de Guaman Poma de Ayala 1615-1616); b) detalle de la tableta de metal con la indicación de las terminaciones laterales y de escote del uncu de sus personajes (flechas blancas) y soldaduras (flechas negras) (Fotografías: M. T. Plaza). Figure 13: a) sheet 757 "Quicia Uillca, $a p u$, lord of the Yauyo lineage that enjoys the favor of the emperor" (taken from Guaman Poma de Ayala 1615-1616); b) detail of the metal tray signaling the lateral sides and neckline of the uncu tunic of the characters (white arrows) and the welds (black arrows) (Photographs by M. T. Plaza).

pantorrillas de los personajes induce a pensar en el uso de calzón bajo el uncu (fig. 13b). En cuanto al tocado o cabello de los personajes de la tableta, el cual pende lateralmente hasta la altura de la nariz de cada uno, es semejante al que presentan las cabezas representadas en las placas circulares coloniales 1338 y 6793 del Pucara de Tilcara (fig. 14; Gluzman 2010).

\section{ANÁLISIS TECNOLÓGICO DE LA TABLETA}

Considerando el gran número de trabajos que compendian las denominadas tabletas de inhalación, junto a la parafernalia psicoactiva asociada (tubo de inhalación, espátula, morterito, entre otros), registradas en Sudamérica tanto a nivel arqueológico como etnográfico (Uhle 1915; Wassén 1965; Torres 1987, 1998; Torres et al. 1991; Llagostera et al. 1988; Sprovieri 2008-2009, entre otros investigadores), las tabletas de metal solo se encuentran en el actual territorio colombiano (Torres 1987, 2018). De acuerdo con Torres (1987), se registran en Colombia catorce tabletas elaboradas en oro y dos en cobre, en los restantes países que este autor releva (Brasil, Bolivia, Perú, Chile y Argentina), el otro único caso de una tableta metálica es la que este trabajo analiza.

Como ya se ha mencionado, Gluzman (2010) estudia cuatro discos metálicos post-hispánicos recuperados en el Pucará de Tilcara aplicando análisis de composición elemental mediante espectrometría de dispersión de energía de rayos X (SEM-EDs); en la tabla 1a transcribimos sus resultados.

Los dos primeros casos (1218 y 1257) serían láminas de aleación plata-cobre, en tanto las piezas 6793 y 1338 estarían elaboradas en cobre no aleado. ${ }^{5}$ En el caso de la placa 1338 la autora indica que la misma habría sido "lograda por fundición. Sus motivos iconográficos son el resultado de incisiones realizadas en un molde en estado fresco previo a su cocción" (Gluzman 2010: 68), a lo cual agrega que las distintas placas coloniales del Pucará de Tilcara se habrían elaborado localmente.

Tras una primera inspección de la tableta de metal, dos aspectos llaman la atención. En primer lugar, el que 


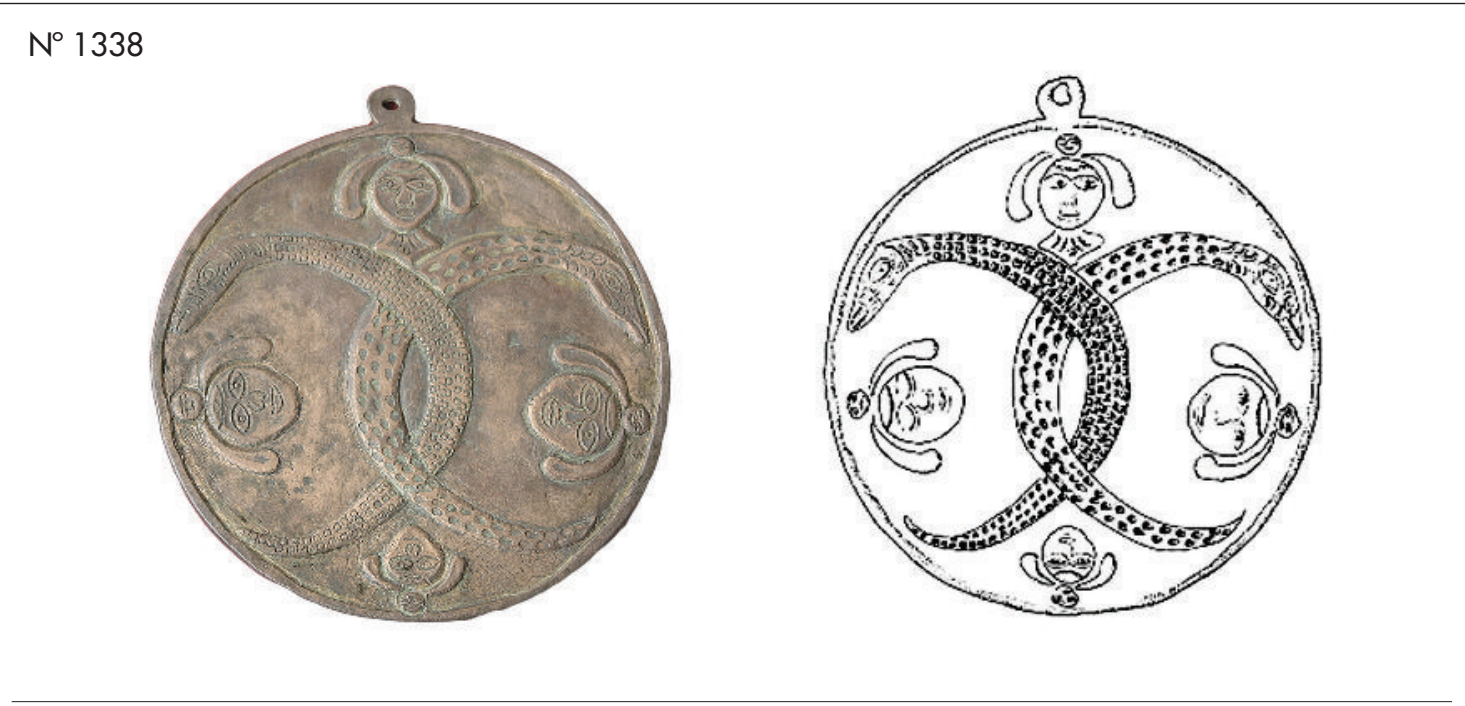

$N^{\circ} 6723$
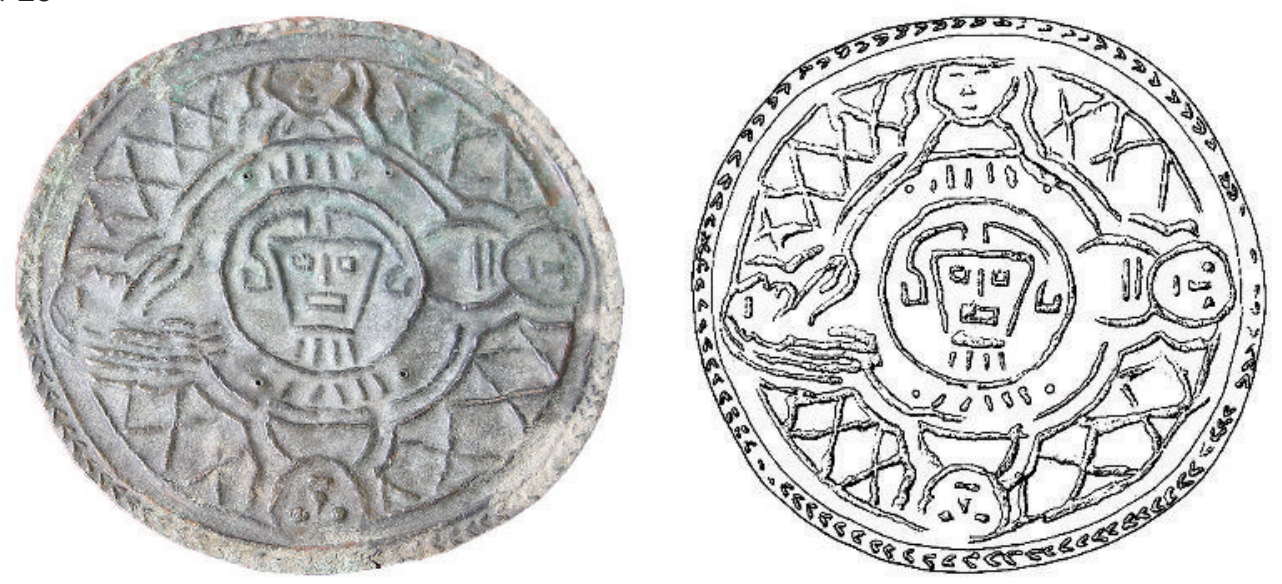

Figura 14. Discos de cobre manufacturados en cobre sin alear encontrados en el Pucará de Tilcara: a) disco 1338; b) disco 6723 (Gluzman 2010: figs. 1e-d, González 1992: lámina 29: 238-239). Figure 14. Copper discs manufactured in unalloyed copper from the Pucará de Tilcara: a) disc 1338; b) disc 6723 (Gluzman 2010: figs. 1e-d, González 1992: sheet 29: 238-239).

los personajes no tengan modelada su parte posterior, como sucede con las tabletas de madera que son producto del tallado volumétrico (Torres 1984, Llagostera 2006), sino que contrariamente el reverso de ambos personajes es liso con leves marcas (fig. 15a). En segundo lugar, en el contacto entre ambos personajes y la cavidad de la tableta existe una aparente soldadura (figs. 15b y $13 \mathrm{~b}$ ).

Con el objeto de profundizar en la manufactura de esta pieza, la tableta fue sometida a un análisis superficial de fluorescencia de rayos-X ("FRXp") que analiza de manera exploratoria y preliminar su composición elemental. Se utilizó un equipo portátil Olympus Delta Innov-X equipado con un detector de $\mathrm{Si}$ (SDD) y un ánodo de Rh de $4 \mathrm{~W}$. Se aplicó un tiempo real de 20s, a $40 \mathrm{keV}, 100 \mu \mathrm{A}$ y se activó el colimador con un diámetro de $5 \mathrm{~mm}$ para analizar áreas pequeñas. Para la cuantificación se utilizó el modo de fábrica pre-establecido "Alloy Plus", con modificaciones especiales para el análisis de metales arqueológicos.

Los resultados entregados corresponden a un promedio de tres análisis sobre superficies no preparadas, si bien se privilegiaron áreas relativamente planas, 
Tabla 1. Composición elemental de: a) los discos del Pucará de Tilcara analizados por Gluzman 2010, tabla 1, y b) la tableta 1491 obtenida por FRxp. Los resultados se entregan normalizados y en porcentaje en peso. Table 1 . Element composition of: $\boldsymbol{a}$ ) the discs from Pucará de Tilcara analyzed by Gluzman 2010, table 1, and b) tablet 1491 obtained by FRXp. The results are normalized and in weight percentage.

\begin{tabular}{|c|c|c|c|c|c|c|c|c|c|}
\hline & $\mathrm{Si}$ & $\mathrm{Al}$ & $\mathrm{Fe}$ & $\mathrm{Cu}$ & $\mathrm{Zn}$ & As & $\mathrm{Ag}$ & $\mathrm{Pb}$ & TOTAL \\
\hline \multicolumn{10}{|c|}{ A. Discos analizados por Gluzman 2010 (SEM-EDS) } \\
\hline 1218 & 1,3 & - & - & 5,0 & - & - & 93,7 & - & 100 \\
\hline 1257 & - & 0,9 & - & 28,1 & - & - & 71,0 & - & 100 \\
\hline 6793 & 1,9 & 2,0 & 0,4 & 95,8 & - & - & - & - & 100 \\
\hline 1338 & 1,4 & 1,0 & 0,8 & 96,8 & - & - & - & - & 100 \\
\hline \multicolumn{10}{|c|}{ B. Análisis de la tableta 1419 (FRXp) } \\
\hline Cavidad tableta, parte posterior & - & - & - & 99,6 & - & 0,4 & - & 0,1 & 100 \\
\hline Personajes del panel, frente & - & - & - & 99,4 & - & 0,5 & - & 0,1 & 100 \\
\hline Soldadura, frente & - & - & 0,6 & 39,5 & 6,8 & - & 52,8 & 0,4 & 100 \\
\hline
\end{tabular}

previamente limpias o raspadas, dónde se observa el metal original sin evidencia de corrosión. Los resultados están normalizados y se entregan en porcentaje en peso. Por la presencia de patinas superficiales, lustre y suciedad, así como por la heterogeneidad estructural de los metales y las imperfecciones geométricas de las piezas, los resultados presentados en este artículo son preliminares y deberán ser confirmados a futuro, analizando secciones más profundas del metal.

La tableta fue analizada en tres sectores: cavidad (parte posterior), personajes (parte anterior) y soldadura (parte anterior). Los resultados se entregan en la tabla 1 b y los espectros en la figura 16. Tanto para la cavidad como para el panel se utilizó cobre sin alear con impurezas de arsénico y plomo, mientras que la soldadura corresponde a una aleación de 39,5\% cobre, $6,8 \%$ zinc y $52,8 \%$ plata con cantidades menores de hierro y plomo.

\section{Aspectos de la manufactura}

Hay datos interesantes en relación a la manufactura de esta pieza. En primer lugar, la calidad de la pieza es muy buena, sobre todo el detalle de los personajes. Si bien, ambos personajes son muy similares, estos no son idénticos, indicando que no fueron hechos a partir de un mismo molde, pero con seguridad fueron elaborados por la misma persona siguiendo un patrón regular y específico.
En segundo lugar, los detalles de la vestimenta con incisiones en forma de $\mathrm{v}$, tales como los bordes decorados de la túnica (véase fig. 13b) y los rebordes suaves y aplanados que se observan en la parte posterior de los personajes (ver brazos y piernas en la fig. 15a), sugieren el uso de un material blando que fue fácilmente modelado. Si bien, es posible el uso de un molde abierto como propone Gluzman para los discos antes mencionados (2010: 67-68), las marcas en la espalda de los personajes podrían indicar el uso de cera, sugiriendo una manufactura a través de la técnica de cera perdida. Ésta técnica es utilizada en el noroeste de Argentina desde períodos prehispánicos para hacer piezas con decoración y figuras complejas (A. González 1992, véase L. González 2004, p. 130 para una descripción detallada). En este caso, dadas las huellas en la parte posterior de los personajes, es muy probable que un molde de arcilla haya cubierto estas figuras de forma completa, tal como lo requiere dicha tecnología.

Si aceptamos la propuesta de que la tableta 1491 pudo haber sido fabricada con la técnica de la cera perdida, la cual permite obtener piezas volumétricas tal como se logra al tallar las tabletas en madera, es notable que en este caso los personajes sean bidimensionales, más similares a los discos y placas de metal del noroeste argentino. Dada la calidad técnica de la pieza, es posible proponer que quien diseñó la tableta lo hizo desde una 

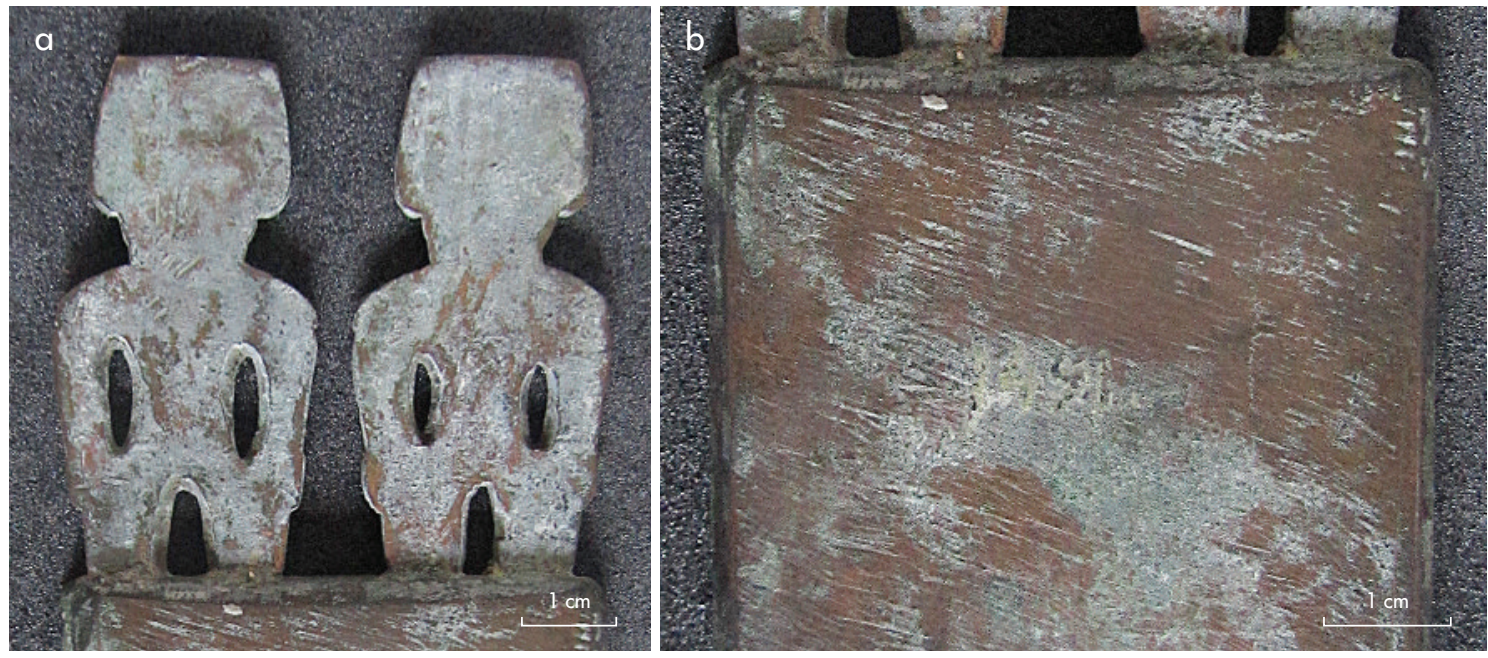

Figura 15. Detalles del proceso de manufactura en metal de la pieza: a) sección posterior del panel. Las flechas indican los rebordes; b) sección posterior de la cavidad con huellas del raspado grueso. (Fotografía: M. T. Plaza). Figure 15. Details of the manufacturing process of the piece in metal: a) back section of the panel. The arrows indicate the edges; b) back section of the cavity with signs of coarse scraping. (Photograph: M. T. Plaza).

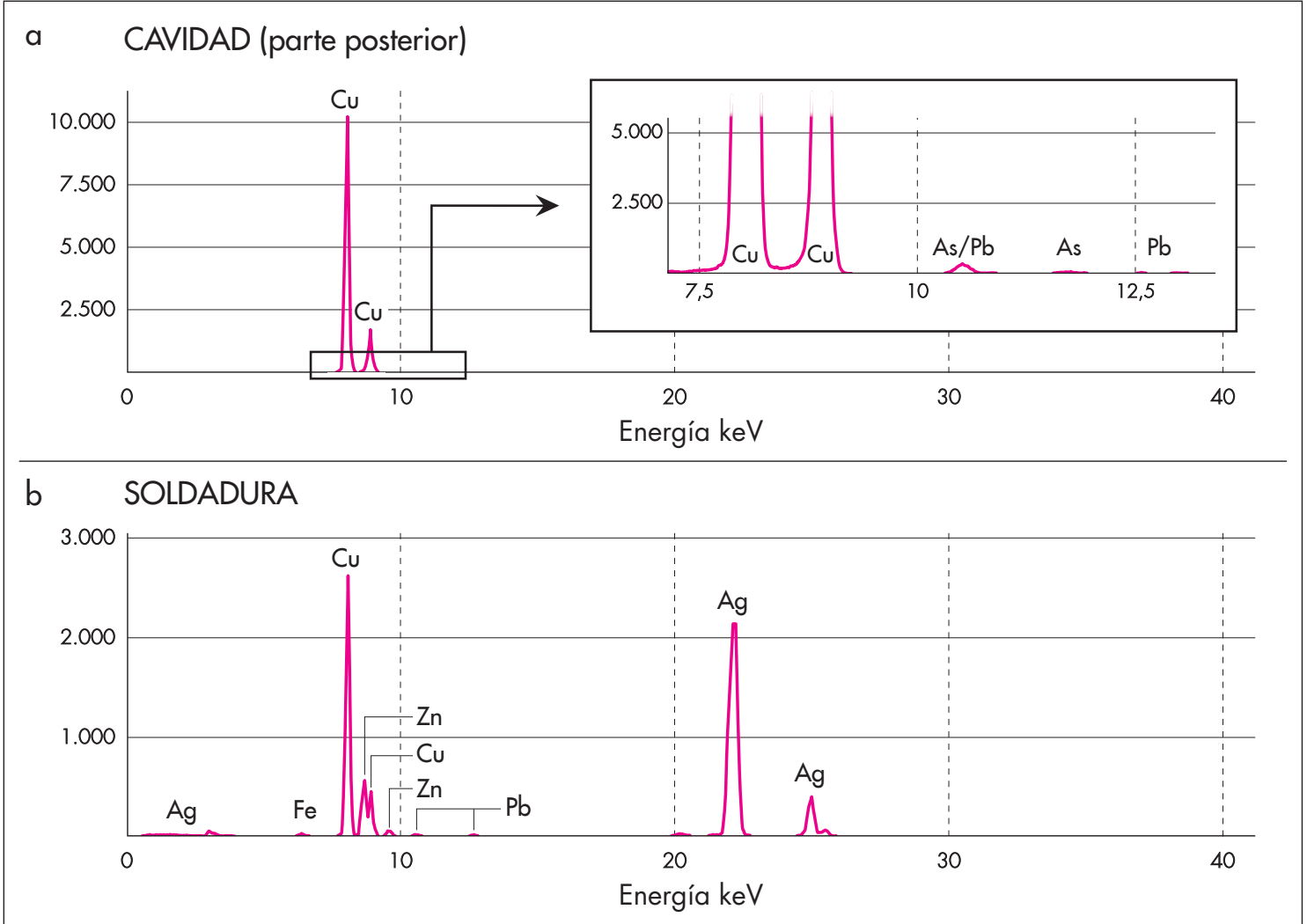

Figura 16. Espectro de fluorescencia de rayos X de: a) la parte posterior de la cavidad de la tableta, la cual es idéntica a la composición de los personajes; b) la soldadura. Los espectros fueron obtenidos con el programa Innov-X Delta Advanced PC Software versión 2, 5, 21, 935. Figure 16. X-ray fluorescence spectrum of: $\boldsymbol{a}$ ) the upper part of the cavity, which is identical in composition to the characters; $\boldsymbol{b})$ the weld. The spectrums were obtained using the software Innov-X Delta Advanced PC Software version 2, 5, 21, 935. 
"forma de hacer" más similar a las placas de metal, que a la de una tableta tradicional. Es decir, parece más probable que la tableta sea el trabajo de un metalurgo versado experimentando con un diseño diferente, en lugar que suponer a un maestro de la madera que experimentó con otra materialidad.

Si los análisis de FRxp son correctos, esta pieza estaría hecha de cobre sin alear. En el noroeste de Argentina, el uso de cobre sin alear es raro y escaso, en comparación con el uso de bronce estañífero o arsenical. Para tiempos tempranos A. González (1979: 153, 159-160) registra una aguja ( $\mathrm{N}^{\circ} 11524: 99,3 \% \mathrm{Cu}, 0,2 \% \mathrm{Fe}$ ) y una campana plegada de cuatro puntas ( $\mathrm{N}^{\circ} 11210: 94,7 \% \mathrm{Cu}$, $0,4 \% \mathrm{Fe}$ y $0,6 \% \mathrm{Si}$ ), fabricadas en cobre sin alear. Mientras que Gluzman (2010) registra al menos dos placas posthispánicas decoradas y hechas en moldes con similares composiciones pertenecientes al Pucará de Tilcara ( $\mathrm{N}^{\circ}$ 6793 y 1338, véanse tabla 1a y fig. 14). El uso de cobre sin alear en objetos hechos por colada es interesante, ya que dicho metal se funde a altas temperaturas $\left(1084^{\circ} \mathrm{C}\right) \mathrm{y}$ se enfría rápidamente, lo que requiere de una tecnología de colada acorde a estas propiedades (y diferente a lo realizado en épocas prehispánicas), y probablemente mucha destreza. Si comparamos la calidad del trabajo, la tableta 1491 es más parecida a la placa 1338 que a la placa 6793 (véase fig. 14).

Otro detalle interesante es el uso de soldaduras (fig. 13b), técnica que no se observa en piezas prehispánicas (A. González 1992, L. González 2004). En este caso las posibilidades son: 1) la soldadura es una reparación, ya sea antigua o moderna ${ }^{6} 0,2$ )es parte de la manufactura de la pieza. Si tomamos en cuenta la primera opción, tendríamos que asumir que ambas figuras se fracturaron y fueron reparadas. Si bien es posible, parece poco probable. La revisión superficial de la pieza, no muestra evidencia de deformaciones o de daños que avalen a simple vista esta opción. La segunda posibilidad indicaría que la pieza fue compuesta originalmente de tres partes: los dos personajes y el cuerpo. Al igual que los personajes, es posible que la cavidad de la tableta también haya sido fabricada en cera perdida, sin embargo, la evidencia obtenida hasta ahora no es suficiente para proponer si se utilizó cera perdida, un molde abierto o cerrado. Las marcas en la parte posterior del panel indicarían que la pieza fue raspada con un material abrasivo grueso, probablemente después de ser fundida (fig. 15b), detalle que no ha sido reportado hasta el momento en piezas prehispánicas.

\section{La soldadura}

La composición de las soldaduras (fig. 13b) es interesante, ya que contienen $6,8 \%$ de zinc. El zinc es un elemento volátil que reacciona y se evapora fácilmente durante la fundición. La única forma de obtener aleaciones con altos contenidos de zinc (entre 15-30\%) en la antigüedad era a partir del método de cementación que mezclaba cobre metálico, mineral de zinc (llamado calamina) y carbón en un crisol cerrado. En este proceso el óxido de zinces reducido a metal a una temperatura de $900-1000^{\circ} \mathrm{C}$. A esta temperatura el zinc en estado metálico se evapora y es fácilmente absorbido por el cobre, formando latón (Rehren 1999a, 1999b; Martinón-Torres et al. 2007). En Europa, evidencias arqueológicas datadas desde el siglo xv indican que éste proceso de cementación se utilizó hasta el siglo XviII, cuando se logra obtener zinc metálico, el cual se mezclaba directamente con cobre metálico para producir latón (Martinón-Torres et al. 2007).

Si bien el uso del latón es común en la Europa medieval, no existe evidencia de cementación en América antes de la llegada de los españoles (Martinón-Torres et al. 2007). En el noroeste argentino, existen aleaciones de cobre con contenidos de zinc bajos, de hasta un 6\% de zinc (A. González 1979, Angiorama 2001), pero se ha propuesto que dichas cantidades son el resultado de la fundición accidental de minerales de cobre ricos en zinc, como por ejemplo crisocola (Patterson 1971, Angiorama 2001, Martinón-Torres et al. 2007). Por su parte Ambrosetti (2011 [1904]), identifica tres discos y un cetro con $c a .13 \%$ de zinc, estaño e impurezas de plomo y hierro que son considerados falsificaciones.

En el caso de la soldadura de la tableta de metal, la cantidad de cobre $(39,5 \%)$ y plata $(52,8 \%)$ indicaría que se trata de una aleación artificial. Mientras que el punto de fusión del cobre es $1084^{\circ} \mathrm{C}$, la aleación de la soldadura compuesta por cobre-zinc-plata con cantidades menores de hierro y plomo, se fundiría alrededor de los $850^{\circ} \mathrm{C}$ (fig. 17), lo que permite unir ambas partes sin afectar el metal original (Schittny \& Lukas 2007: fig. 2). El uso de esta aleación sugiere una intencionalidad por parte del orfebre, quien conocía y manejaba las propiedades de ambos metales.

Aunque la plata puede contener impurezas de zinc, como demuestra el análisis de un objeto de Ciénaga Grande publicado por Angiorama (2001: tabla 24) con $91 \%$ plata, $4,8 \%$ cobre, $2,4 \%$ zinc y $1,5 \%$ hierro, o tres figurillas Incas analizadas por Guerra et al. (2017: tabla 
2) de $95,3-98,5 \%$ plata con $0,1 \%$ zinc, estas cantidades de zinc son muy bajas para explicar el casi $7 \%$ de zinc en la aleación de la tableta 1491. Es más probable en este caso que la mezcla haya incluido el uso de plata y latón (una aleación de cobre y zinc). Si asumimos que la soldadura es parte de la manufactura original de la tableta, esta composición ubicaría la pieza en una época post-contacto, aunque no es posible proponer un rango de tiempo más específico.

Para estimar el valor original del latón utilizado, y considerando que éste en general contiene muy poca plata (generalmente menos de $0,1 \%$, aunque algunos latones europeos de 1475-1500 pueden tener hasta $0,5 \%$ plata), se normalizaron los porcentajes del cobre y zinc a un $100 \%$, resultado en un latón con composición aproximada de $85,4 \%$ de cobre y $14,6 \%$ de zinc (aunque es posible que la cantidad original de zinc sea mayor, ya que parte del elemento se habría evaporado durante su aleación con plata). El FRxp no detectó níquel ni estaño, ${ }^{7}$ elementos comunes en latones de ciertas partes de Europa (Mitchiner et al. 1987). Sí se identificaron cantidades menores de hierro y plomo.

Mitchiner y colegas (1987) publican una base de datos de medallones de latón (jetons) producidos en Europa entre 1400-1800. En general, los latones producidos por cementación entre los siglos XIV-XVII, contienen $\sim 11-30 \%$ zinc, con cantidades menores $(<1 \%)$ de níquel, estaño, plomo, hierro, antimonio y plata (Mitchiner et al. 1987). Son pocas las composiciones similares a la de la soldadura de la tableta 1491 con 14$18 \%$ zinc, trazas de plomo y hierro, pero sin níquel o estaño. Identificamos seis piezas en total: un ejemplar datado entre 1480-1500, tres entre 1500-1550, uno entre $1600-1650$ y otro entre $1750-1800{ }^{8}$

En Cuba, se han encontrado objetos de latón en sitios indígenas, adquiridos durante el contacto con europeos entre los siglos XV-XVI. Dichos latones presentaron niveles de zinc entre $15-26 \%$, con cantidades menores de plomo $(\leq 1,7 \% \mathrm{~Pb})$, plata, hierro, níquel y en algunos casos estaño (Martinón-Torres et al. 2007). Mientras que Vetter y Guerra registran una estatuilla inca hecha en latón con $43 \%$ cobre, $43 \%$ zinc, $1 \%$ hierro y $11 \%$ níquel, la cual es considerada por las autoras como una figurilla manufacturada durante el Período Colonial (Vetter \& Guerra 2017: 182).

Por otro lado, el latón con alrededor de $15 \%$ zinc produce un color semejante al del oro, razón por la cual se hizo muy popular en Europa durante el siglo XviII como substituto de este metal precioso. En dicha época el zinc comenzó a ser producido en estado metálico, lo que permitió que se agregara de forma controlada y medida a la aleación (Selwyn 2004: 54). Con esta aleación se fabricaron joyas que imitaban piezas de oro, cajitas, relojes y botones (Selwyn 2004: 54) que pudieron ser fácilmente importadas a América. La falta de estaño y níquel bien podría indicar el uso de un metal importado más tardío, aunque se necesitan análisis adicionales para confirmar la ausencia de dichas impurezas.

\section{CONCLUSIONES}

Resumiendo los aportes de los datos contextuales, iconográficos y tecnológicos que hemos analizado aquí, podemos establecer que la tableta de metal no constituye un artefacto de fabricación prehispánica, sino de data post-hispánica. Junto con ello, y observando su iconografía alusiva a elementos de la imaginería pre-Conquista, es plausible suponer un cambio en su función original como tableta para inhalar sustancias psicoactivas. Podría darse el caso de la resignificación del objeto, como hemos supuesto en un trabajo anterior sobre una tableta de madera prehispánica en contexto colonial temprano, al interior de un nuevo rito relacionado con la fertilidad vegetal (Horta et al. 2016).

En relación con las cruces labradas en los personajes de la tableta, no hay duda que fueron concebidas como dos tipos diferentes entre sí y que, por lo tanto, el aguzamiento que presentan los brazos de las cruces ubicadas en el pecho de las figuras humanas no es producto de un acto involuntario. Esta situación sugiere el manejo consciente de un mensaje apropiado para un período de transición cultural como el que se vivía en tiempos post-Conquista. Por otra parte, un aspecto que resulta igualmente notable es la combinación de elementos prehispánicos y andino-coloniales en un objeto que forma parte de un contexto de poder y prestigio utilizado por las elites políticas y sociales nativas. De esta manera, no solo se reconoce una continuidad en la valoración del objeto mismo, sino además, una transferencia de parte de la semántica andina colonial, la cruz de extremos aguzados o romboides, al artefacto inhalatorio. Esto lleva a pensar en la capacidad de las elites andinas para incorporar elementos cristianos a sus prácticas culturales, sin que por ello sus objetos antiguos (convertidos en reliquias a ojos hispanos) perdiesen sus valores originales; por 


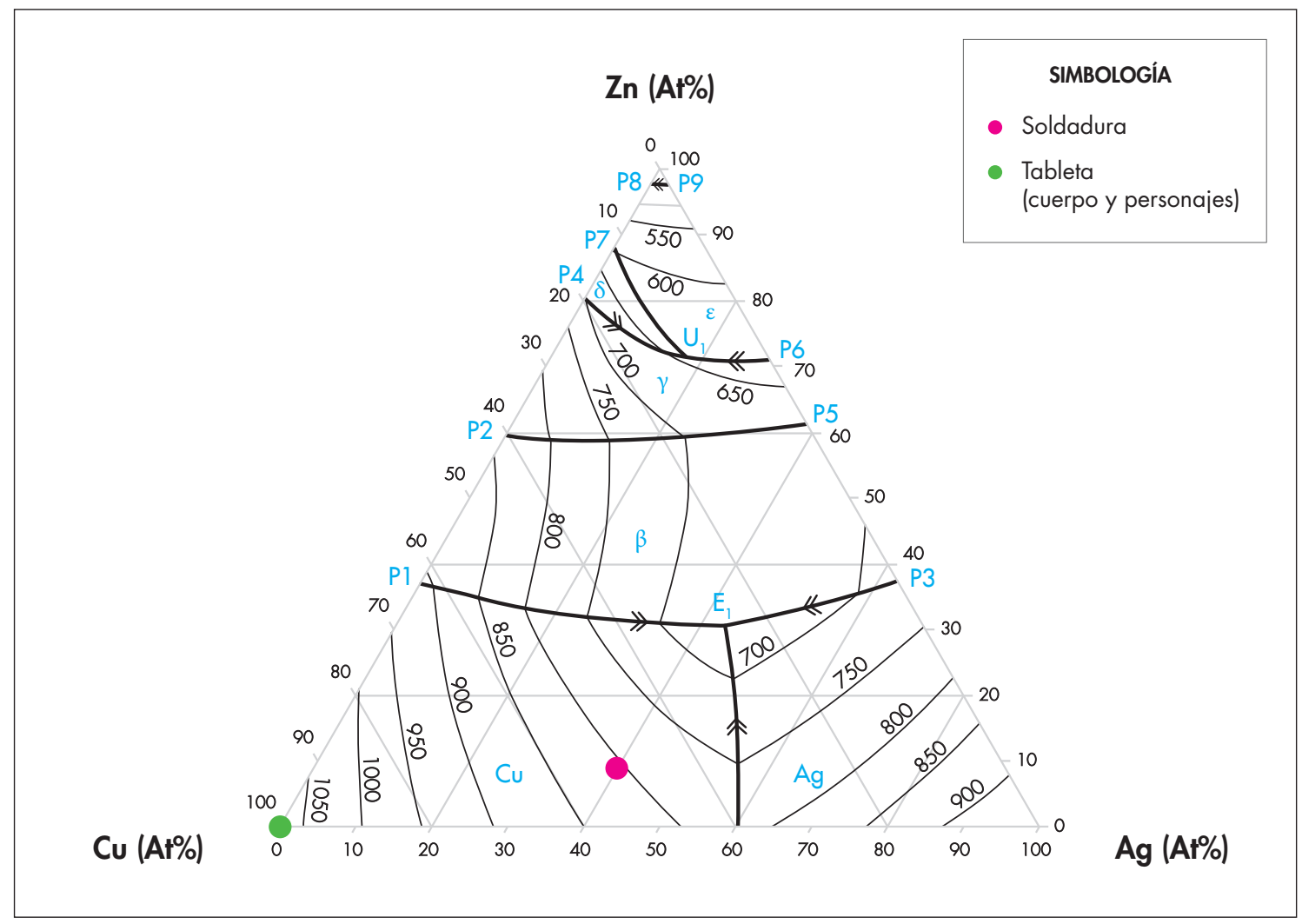

Figura 17. Diagrama ternario zinc-plata-cobre mostrando las temperaturas a las que la aleación se funde (metal en estado líquido, Schittny \& Lukas, 2007, fig. 2). En rojo se indica la soldadura de la tableta 1491 que se liquidifica a $850{ }^{\circ} \mathrm{C}$, mientras que el cobre se funde a $1084^{\circ} \mathrm{C}$. Los resultados del diagrama están dados en peso atómico (at\%): 51,2\% Cu, 8,5\% Zn y 40,3\% Ag. Figure 17. Zn- $\mathrm{Ag}$ - Cu Ternary diagram showing the temperatures at which the alloy melts (metal in liquid state, Schittny \& Lukas, 2007, fig. 2). In red I the weld of tablet 1491 which liquifies at $850{ }^{\circ} \mathrm{C}$, while copper melts at $1,084^{\circ} \mathrm{C}$. The results of the diagram are in atomic weight (at\%): $51.2 \% \mathrm{Cu}$, 8.5\% $\mathrm{Zn}$ and $40.3 \% \mathrm{Ag}$.

el contrario, estos se habrían enriquecido y entrado en diálogo con las nuevas realidades hispano-coloniales.

Respecto de la autenticidad de la pieza, creemos que es posible confirmarla tras la sumatoria de evidencias que aquí hemos presentado. Si bien éstas no son conclusivas, es lo que permite una aproximación rigurosa a una pieza excepcional que no se puede fechar, pero que es de especial relevancia por sus características intrínsecas.

Los aspectos siguientes indican que la pieza no es falsa, esto es, fabricada en tiempos contemporáneos con el objeto de aparentar antigüedad, ya sea prehispánica o colonial. En primer lugar, si fuera la única pieza metálica colonial del Pucará de Tilcara, eso haría dudar de su atenticidad, pero no solo existe un componente de entierros coloniales con ajuar destacado muy importante, tanto en Tilcara Pueblo como en el Pucará, sino que entre las placas analizadas por Gluzman (2010) hay al menos una que, al igual que la tableta, combina de manera muy precisa elementos pre y post-Conquista. En este sentido es muy probable que la tableta haya sido recuperada también por Schuel y proceda de los mismos contextos o de otros muy cercanos a los de proveniencia de las placas metálicas del Pucará de Tilcara, como sugiriera González en su momento (1992).

En segundo lugar, desde el punto de vista tecnológico, al comparar esta pieza con discos que se consideran falsos (González 1992, figs. 415-418; Ambrosetti 2011 [1904]: figs. 86, 97-99), la calidad de la tableta es bastante superior mostrando un trabajo de gran habilidad $y$ calidad que no se ha observado hasta ahora en otras falsificaciones. Por otro lado, el uso de cobre sin alear, casi ausente en época prehispánica, pero reportado en piezas post-hispánicas (Gluzman 2010), y soldaduras que incluyen una aleación con zinc, reforzarían una temporalidad post-Conquista.

Finalmente, hemos visto que la tableta guarda coherencia con ciertos rasgos del estilo Circumpuneño. Asimismo, lo que presenta de post-hispánico no es tampoco extremadamente raro, atípico o no vinculable con otras manifestaciones iconográficas coloniales 
tempranas, tal como hemos visto en relación con los trabajos sobre cruces coloniales. Resulta muy coherente, además, la continuidad y el cambio en el texto iconográfico de la tableta, situación que haría de un supuesto falsificador un erudito en representaciones andinas pre y post-Conquista.

Agradecimientos Agradecemos la buena disposición y las facilidades que nos prestaran en el acceso a colecciones los colegas Dra. Laura Miotti, Jefa de la División Arqueología y del Dr. Mariano Bonomo, SubJefe de la División Arqueología, Facultad de Ciencias Naturales y Museo de la Universidad Nacional de La Plata. También a la Dra. Carolina Rivet, por el asesoramiento bibliográfico y al Instituto de Arqueología de la University College London, quienes facilitaron el equipo de fluorescencia de rayos-x portátil. Debemos mencionar que esta investigación se realizó en el marco del proyecto FONDECYT 1160849, titulado "Estudio multidisciplinario del sistema religioso atacameño: parafernalia alucinógena, cronología y diferenciación social (500-1500 DC)".

\section{NOTAS}

${ }^{1}$ Parece probable que el sitio cuente además con ocupaciones de finales del Período Formativo (700 a 900 DC) (Zaburlín 2009), lo cual daría sentido a ciertos hallazgos efectuados en dicho sitio, como el de una pipa de piedra (Zaburlín \& Otero 2014).

${ }^{2}$ Gluzman (2010, tabla 3) transcribe y clasifica las referencias que aporta A. González (1992) en su libro "Las placas metálicas de los Andes del Sur", destacando la presencia de 13 placas procedentes del Pucará de Tilcara de un total de 31 placas procedentes de la provincia de Jujuy. De las 13 placas mencionadas, la mayoría fue probablemente confeccionada en plata, una en oro, una en cobre o bronce y dos son aparentemente aleaciones. En general, son circulares con cuatro orificios en el centro. En tres casos hay representaciones de ofidios y la mayoría de los ejemplares son asignados por González al período Imperial o Hispano-Indígena.

${ }^{3}$ Esta semejanza estilística fue observada previamente por Raffino (1983: 190).

${ }^{4}$ Véanse las láminas Portada, 2, 14, 17, 19, 33, 35, 37, 39, $42,46,92,375,386,402,406,419,430,438,440,466,470$, $484,517,558,633,639,643,645,649,651,653,666,678,687$, $689,692,713,717,753,755,757,759,763,765,767,769,771$, $775,784,806,808,818,825,828,835,837,847,900,930,933$, 946, 949, 952, 1001-1002, 1005, 1071.

${ }^{5}$ Dado que los análisis de estos discos son superficiales, es muy probable que la presencia de $\mathrm{Si}$ y $\mathrm{Al}$ se deban a conta- minación superficial o impurezas, más que a elementos añadidos al cobre.

${ }^{6}$ Ver por ejemplo Arenas (2008) para el caso de la soldadura moderna del Disco Lafone Quevedo.

${ }^{7}$ Recalcamos en esta discusión el carácter preliminar de los resultados entregados. Detectar estaño utilizando el FRXp en una aleación rica en plata es complicado, porque el instrumento no siempre distingue el estaño. Las líneas espectrales de la plata $(\mathrm{K} \beta 24,9 \mathrm{keV})$ y el estaño (Ka 25,0keV) se sobreponen, ocultando el elemento que se encuentra en menor cantidad.

${ }^{8}$ Entre 1480-1500, medalla No 22 con $15,8 \% \mathrm{Zn}, 0,06 \% \mathrm{Ni}$ y sin Sn. Entre 1500-1550 medallas No 33, 37 y 51 con $17-$ $18 \% \mathrm{Zn}$, sin Ni o Sn. Entre 1600-1650, medalla No 113 con $16,9 \% \mathrm{Zn}, 0,02 \% \mathrm{Ni}$, sin Sn; y entre 1750-1800 medalla No 248 con $15,4 \% \mathrm{Zn}$, sin Ni o Sn (Mitchiner et al. 1987).

\section{REFERENCIAS}

Ambrosetti, J. B. 1902. Antigüedades calchaquíes. Datos arqueológicos sobre la provincia de Jujuy, LII, LIII, LIV. Buenos Aires: Anales de la Sociedad Científica Argentina.

Ambrosetti, J. B. 1908. Exploraciones arqueológicas en la ciudad prehistórica de La Paya (valle Calchaquí, Provincia de Salta): campañas de 1906 y 1907. Primera y segunda parte. Revista de la Universidad de Buenos Aires, Publicaciones de la Sección Antropología 3.

Ambrosetti, J. B. 2011 [1904]. El bronce en la región Calchaquí. Buenos Aires: Editorial de la Facultad de Filosofía y Letras de la Universidad de Buenos Aires.

Angiorama, C. 2001. De metales, minerales y yacimientos. Contribución al estudio de la metalurgia prehispánica en el extremo noroccidental de Argentina. Estudios Atacameños 21: 63-87.

Arena, M. D. 2008. Documentación e identidad de los materiales arqueológicos del Museo de La Plata. Museo 3 (22): 3-13.

Arenas, M. A. 2011. Representaciones rupestres en los Andes coloniales. Una mirada desde el sitio Toro Muerto (comuna de La Higuera, IV Región de Coquimbo-Chile). Tesis para optar al título de Antropólogo y al grado de Licenciado en Antropología, Universidad Academia de Humanismo Cristiano, Santiago.

Arenas, M. A. \& Odone, M. C. 2015. Cruz en la piedra. Apropiación selectiva, construcción y circulación de una imagen cristiana en el arte rupestre andino colonial. Estudios Atacameños 51: 137-151.

Balesta, B. \& Zagorodny, N. 2000. Memorias e intimidades de una colección arqueológica. Revista Relaciones de la Sociedad Argentina de Antropología Xxv: 41-50.

Blanco, J. F., De la Maza, M. \& Peñaloza, M. A. 2015. Memoria inscrita. Arte rupestre de contacto, integración y dominación en el centro-sur de Chile. Boletín del Museo Chileno de Arte Precolombino 20 (2): 89-110. 
Berenguer, J. 2004. Cinco milenios de arte rupestre en los Andes atacameños: imágenes para lo humano, imágenes para lo divino. Boletín del Museo Chileno de Arte Precolombino 9: 75-108.

Casanova, E. 1950. Restauración del Pucará. Buenos Aires: Instituto de Antropología, Facultad de Filosofía y Letras, Universidad de Buenos Aires.

Cruz, P. 2006. Mundos permeables y espacios peligrosos. Consideraciones acerca de punkus y qaqas en el paisaje altoandino de Potosí, Bolivia. Boletín del Museo Chileno de Arte Precolombino 11 (2): 35-50.

Gluzman, G. 2010. Estudios técnicos y estilísticos en discos metálicos hispano-indígenas procedentes del Pukará de Tilcara (Jujuy, Argentina). Boletín del Museo Chileno de Arte Precolombino 15 (1): 63-80.

GonzÁlez, A. 1972. The felinic complex in northwest Argentina. En The cult of the feline, E. Benson, Ed., pp. 117-138. Washington: Dumbarton Oaks.

González, A. 1979. Precolumbian metallurgy of Northwest Argentina: historical development and cultural process. En Precolumbian metallurgy of South America, E. Benson, Ed., pp. 133-202. Washington: Dumbarton Oaks.

GonzÁlez, A. 1992. Las placas metálicas de los Andes del sur. Contribución al estudio de las religiones precolombinas. Maguncia: Philipp von Zabern.

González, A. 1998. Cultura La Aguada. Arqueología. Buenos Aires: Filmediciones Valero.

GONZÁLEZ, L. 2004. Bronces sin nombre. La metalurgia prehispánica en el norte argentino. Buenos Aires: Fundación Ceppa.

Guaman Poma de Ayala, F. 1980 [1615]. El primer nueva corónica y buen gobierno. Ciudad de México: Siglo XxI.

Guerra, M. F., Fischer, M., Radtke, M. \& Reinholz, U. 2017. Inca figurines from the Ethnologisches Museum in Berlin: an analytical study of some typical and atypical productions. Bulletin de l'Institut Français d'Études Andines 46 (1): 221-251.

Horta, H. 2004. Iconografía del Formativo Tardío del norte de Chile: propuesta de definición e interpretación basada en imágenes textiles y otros medios. Estudios Atacameños 27: $45-76$.

Horta, H. 2012. El estilo Circumpuneño en el arte de la parafernalia alucinógena prehispánica (Atacama y Noroeste Argentino). Estudios Atacameños 43: 5-34.

Horta, H., Hidalgo, J. \& Figueroa, V. 2016. Transformación y resignificación de la parafernalia alucinógena prehispánica en Atacama a la luz de un documento del siglo XVII. Estudios Atacameños 53: 93-116.

Hostnig, R. 2004. Arte rupestre postcolombino de la Provincia Espinar, Cusco, Perú. Boletín SIARB 18: 40-64.

Krapovickas, P. 1958-1959. Arqueología de la Puna argentina. Anales de Arqueología y Etnología 14-15: 53-113.

Lafone Quevedo, S. 1892. Catálogo descriptivo e ilustrado de las huacas de Chañar Yaco (Provincia de Catamarca). Revista del Museo de La Plata 3: 35-63.
LLagostera, A. 2006. Contextualización e iconografía de las tabletas psicotrópicas Tiwanaku de San Pedro de Atacama. Chungara 38 (1): 83-111.

Llagostera, A., Torres, C. \& Costa, M. A. 1988. El complejo psicotrópico en Solcor-3 (San Pedro de Atacama). Estudios Atacameños 9: 61-98.

MartíneZ, J. L. 2009. Registros andinos al margen de la escritura: el arte rupestre colonial. Boletín del Museo Chileno de Arte Precolombino 14 (1): 9-35.

Martínez, J. L. \& Arenas, M. A. 2008. Problematizaciones en torno al arte rupestre colonial en las áreas centro sur y meridional andina. En Crónicas sobre la piedra. Arte rupestre de las Américas, M. Sepúlveda, L. Briones \& J. Chacama. Eds., pp. 129-140. Arica: Ediciones de la Universidad de Tarapacá.

Martínez, J. L. \& Arenas, M. A. 2009. Iglesia en la piedra: representación rupestre y evangelización en los Andes del sur. En La vitalidad de las voces indígenas: arte rupestre del contacto y en sociedades coloniales, F. Berrojalbiz, Ed., pp. 9-32. Oaxaca: Ediciones unAm.

Martinón-Torres, M., Rojas, R. V., Cooper, J. \& Rehren, T. 2007. Metals microanalysis and meaning: a study of metal objects excavated from the indigenous cemetery of The Chorro de Maíta, Cuba. Journal of Archaeological Science 34 (2): 194-204.

MAYER, E. F. 1986. Armas y herramientas de metal prehispánicas en Argentina y Chile. Materialien zur Allgemeinen und Vergleichenden Archäologie, AVA-Materialien 53. Munich: Verlag C.H. Beck.

Mitchiner, M. B., Mortimer, C. \& Pollard, A. M. 1987. Nuremberg and its Jetons, c. 1475 to 1888 : chemical compositions of the alloys. The Numismatic Chronicle 147: 114-155.

Moralejo, R. 2010. Las Huacas de Chañar Yaco: importancia y significado de su revisión. Revista Española de Antropología Americana 40 (2): 51-76.

Nielsen, A. 2018. La parafernalia para consumo de alucinógenos de "Calilegua" (Jujuy, Argentina): procedencia, cronología y relaciones circumpuneñas. Boletín del Museo Chileno de Arte Precolombino 23 (1): 71-100.

Otero, C. 2013. Producción, usos y circulación de bienes en el Pucará de Tilcara (Quebrada de Humahuaca, Jujuy). Tesis para optar al grado de Doctora en Arqueología, Facultad de Filosofía y Letras, Universidad de Buenos Aires.

Oyarzún, A. 1971 [1933]. Las tabletas y los tubos para preparar la paricá en Atacama. En Estudios Antropológicos y arqueológicos, M. Orellana, Comp., pp. 112-120. Santiago: Universitaria.

Pacheco, A., Retamal, R. \& MéndeZ-Quirós, P. 2016. Violence in Northern Chile during the Late Intermediate Period (AD 1000-1450). Revisited utilising Three Archaeological Indicators. En Beyond war: archaeological approaches to violence, A. García Piquer \& A. Vila-Mitjá, Eds., pp. 23-47. Cambridge: Cambridge Scholars Publishing. 
Patterson, C. 1971. Native copper, silver and gold accessible to early metallurgists. American Antiquity 36 (03): 286-321.

Posnansky, A. 1945. Tiahuanaco. La cuna del hombre americano. Tomo I. Nueva York: Columbian University.

Quiroga, A. 1898. El simbolismo de la cruz y el falo calchaquí. Boletín del Instituto Geográfico Argentino xIX: 305-318.

QuirogA, A. 1977 [1901]. La cruz en América. Buenos Aires: Castañeda.

RAFrino, R. 1983. Los Inkas del Kollasuyu. Origen, naturaleza y transfiguraciones de la ocupación inka en los Andes meridionales. La Plata: Ramos Americana.

ReHren, T. 1999a. Small size, large scale roman brass production in Germania inferior. Journal of Archaeological Science 26 (8): 1083-1087.

Rehren, T. 1999b. The same... but different: A juxtaposition of roman and medieval brass making in central Europe. En Metals in Antiquity, S. Young, A. Pollard, P. Budd, \& R. Ixer, Eds., pp. 225-257. Oxford: Archaeopress.

Rivet, M. C. 2013. Cruces e iglesias en un contexto chullpario: arte rupestre colonial en las tierras altas atacameñas. Nuevo Mundo, Mundos Nuevos. <http://nuevomundo.revues. org /64960> [consultado: 10-03-2020] ISSN 1626-0252.

SANFuENTES, O. 2008. Invenciones iconográficas en América. El caso de Santo Tomás y el de Santiago mata-indios. Diálogo andino 32: 45-58.

Sanfuentes, O. 2016. San Santiago de Belén. Un guerrero más allá de las fronteras. En Fronteras: procesos y prácticas de integración y conflicto entre Europa y América (siglos XVI-XX), V. Favarò, M. Merluzzi \& G. Sabatini, Eds., pp. 165-180. Ciudad de México: Fondo de Cultura Económica.

Schittny, S. \& Lukas, H. L. 2007. Silver-copper-zinc. En Non-ferrous metal systems. Part 3: Selected soldering and brazing systems, G. Effenberg \& S. Ilyenko, Eds., pp. 75-85. Berlín: Springer Berlin Heidelberg.

Selwyn, L. 2004. Metals and corrosion. A handbook for the conservation professional. Ottawa: Minister of Public Works and Government Services.

Sinclaire, C. 1997. Pinturas rupestres y textiles formativos en la región atacameña: paralelos iconográficos. Estudios Atacameños 14: 327-338.

SProvieri, M. 2008-2009. Alucinaciones en circulación. Una mirada a la interacción surandina tardía desde las tabletas y tubos de La Paya (Valle Calchaquí, Salta). Anales de Arqueología y Etnología 63-64: 81-105.

Strecker, M. 1992. Arte rupestre colonial de Betanzos, Dpto. de Potosí, Bolivia. En Arte rupestre colonial y republicano de Bolivia y países vecinos, R. Querejazu, Ed., pp. 95-102. La Paz: Sociedad de Investigación del Arte Rupestre de Bolivia.

TAвOADA, F. 1992. El arte rupestre indígena de Chirapaca, Dpto. de La Paz, Bolivia. En Arte rupestre colonial y republicano de Bolivia y países vecinos, R. Querejazu, Ed., pp. 111-167. La Paz: Sociedad de Investigación del Arte Rupestre de Bolivia.
Torres, M. C. 1984. Tabletas para alucinógenos de San Pedro de Atacama: estilo e iconografía. En Tesoros de San Pedro de Atacama. Santiago: Museo Chileno de Arte Precolombino.

Torres, M. C. 1987. The iconography of South American snuff trays and related paraphernalia. Etnologiska Studier 37. Gotemburgo: Göteborgs Etnografiska Museum.

Torres, M. C. 1998. Psychoactive substances in the archaeology of Northern Chile and NW Argentina. Chungara 30: 49-63.

Torres, M. C. 2018. The use of psychoactive plants by ancient indigenous populations of the North Andes. Journal of Psychedelic Studies: 1-14. <https://akademiai.com/doi/ pdf/10.1556/2054.2018.015> [consultado: 12-06-2019].

Torres, M. C., Repke, D. B., Chan, K., Mackenna, D., Llagostera, A. \& Schultes, R. E. 1991. Snuff powders from Pre-Hispanic San Pedro de Atacama: chemical and contextual analysis. Current Anthropology 32: 640-649.

Uhle, M. 1915. Los tubos y tabletas para rapé de Chile. Revista Chilena de Historia y Geografía XVI (20): 114-136.

Vetter, L. \& Guerra, M. F. 2017. Los tupus y estatuillas de plata inka: una aproximación a sus aleaciones. Bulletin de l'Institut français d'études andines 46 (1): 171-192.

VON BRUnN, R. 2009. Metamorfosis y desaparición del vencido: desde la subalternidad a la complementariedad en la imagen de Santiago ecuestre en Perú y Bolivia. Tesis de Magíster en Artes con mención en Teoría e Historia del Arte, Facultad de Artes, Universidad de Chile.

Von Rosen, E. 1924. Popular account of archaeological research during the swedish Chaco-cordillera-expedition 1901-1902. Estocolmo: C. E. Fritzes.

WAssén, S. H. 1965. The use of some specific kinds of South American Indian snuffs and related paraphernalia, Etnologiska Studier 28. Gotemburgo: Göteborgs Etnografiska Museum.

Zaburlín, M. A. 2009. Historia de ocupación del Pucará de Tilcara (Jujuy, Argentina). Intersecciones en Antropología 10: 89-103.

Zaburlín, M. A. \& Otero, C. 2014. Un manuscrito olvidado de J. B. Ambrosetti: "Exploraciones arqueológicas en la antigua ciudad del Pukara de Tilcara". En Colección Saberes, investigaciones del Instituto Interdisciplinario Tilcara, M. E. Aparicio, A. Benedetti, L. Bugallo, L. Mamani, P. Mercolli, M. Montenegro, C. Otero, L. Paredes, C. Rivet, J. Tomasi, M. Weinberg \& M. A. Zarbulin, Eds., pp. 161220. Tilcara: Editorial de la Facultad de Filosofía y Letras de la Universidad de Buenos Aires. 